\title{
Application of Object-Based Time-Domain Diagnostics for Tracking Precipitation Systems in Convection-Allowing Models
}

\author{
ADAM J. CLARK \\ Cooperative Institute for Mesoscale Meteorological Studies, University of Oklahoma, and NOAA/OAR/National \\ Severe Storms Laboratory, Norman, Oklahoma \\ RANDY G. BULlOCK AND TARA L. JENSEN \\ Developmental Testbed Center, Boulder, Colorado \\ Ming XUE \\ Center for Analysis and Prediction of Storms, and School of Meteorology, University of Oklahoma, Norman, Oklahoma \\ FANYOU KONG \\ Center for Analysis and Prediction of Storms, University of Oklahoma, Norman, Oklahoma
}

(Manuscript received 12 August 2013, in final form 18 December 2013)

\begin{abstract}
Meaningful verification and evaluation of convection-allowing models requires approaches that do not rely on point-to-point matches of forecast and observed fields. In this study, one such approach-a beta version of the Method for Object-Based Diagnostic Evaluation (MODE) that incorporates the time dimension [known as MODE time-domain (MODE-TD)] —was applied to 30-h precipitation forecasts from four 4-km grid-spacing members of the 2010 Storm-Scale Ensemble Forecast system with different microphysics parameterizations. Including time in MODE-TD provides information on rainfall system evolution like lifetime, timing of initiation and dissipation, and translation.

The simulations depicted the spatial distribution of time-domain precipitation objects across the United States quite well. However, all simulations overpredicted the number of objects, with the Thompson microphysics scheme overpredicting the most and the Morrison method the least. For the smallest smoothing radius and rainfall threshold used to define objects [ $8 \mathrm{~km}$ and $0.10 \mathrm{in}$. $(1 \mathrm{in} .=2.54 \mathrm{~cm})$, respectively], the most common object duration was $3 \mathrm{~h}$ in both models and observations. With an increased smoothing radius and rainfall threshold, the most common duration became shorter. The simulations depicted the diurnal cycle of object frequencies well, but overpredicted object frequencies uniformly across all forecast hours. The simulations had spurious maxima in initiating objects at the beginning of the forecast and a corresponding spurious maximum in dissipating objects slightly later. Examining average object velocities, a slow bias was found in the simulations, which was most pronounced in the Thompson member. These findings should aid users and developers of convection-allowing models and motivate future work utilizing time-domain methods for verifying high-resolution forecasts.
\end{abstract}

\section{Introduction}

Useful verification and evaluation of convectionallowing models ${ }^{1}$ requires "nontraditional" approaches

\footnotetext{
${ }^{1}$ The term convection allowing refers to simulations that explicitly depict convection (i.e., do not use convective parameterization) but that do not use high enough resolution to adequately resolve processes like turbulence and entrainment within clouds. The term generally describes simulations run with 3-4-km horizontal grid spacing.

Corresponding author address: Adam J. Clark, National Weather Center, NSSL/FRDD, 120 David L. Boren Blvd., Norman, OK 73072. E-mail:adam.clark@noaa.gov
}

that do not rely on point-to-point matches of forecast and observed fields (e.g., Roberts and Lean 2008; Casati et al. 2008; Clark et al. 2010, and many others). These nontraditional approaches are needed because, as grid resolution increases, the time scales at which very accurate predictability is possible on the grid scale become very short (e.g., Lorenz 1969). Thus, even for forecasts that humans would consider very good because they capture some feature of interest at about the right location and time, double penalties (i.e., forecast but not observed, observed but not forecast) will harshly penalize traditional metrics.

One approach for nontraditional verification is objectbased verification in which objects are contiguous regions 
of grid points of a particular field exceeding a specified threshold. After objects are defined, pattern recognition techniques are applied to match forecast to observed objects. Attributes of matched objects such as location, intensity, and shape can be compared to evaluate their degree of similarity. Various object-based approaches have been documented including the contiguous-rainarea method (Ebert and McBride 2000; Ebert and Gallus 2009), compositing methods (e.g., Nachamkin 2004), multiscale object identification (Lack et al. 2010) and the structure, amplitude, and location (SAL) measure (Wernli et al. 2008).

Herein, we utilize an object-based approach known as the Method for Object-Based Diagnostic Evaluation (MODE; Davis et al. 2006a; Davis et al. 2009), which is part of the Developmental Testbed Center's (DTC) Model Evaluation Tools (MET; current version available online at http://www.dtcenter.org/met/users/downloads/). In MODE, objects are defined within a spatial field after application of smoothing and thresholding. Then, fuzzylogic-based algorithms can be applied to match and/or merge objects in forecast and observed fields.

Many recent studies have demonstrated meaningful diagnostics by applying MODE to convection-allowing forecasts. Davis et al. (2006b) examined rainfall forecasts over the central United States from a 4-km gridspacing configuration of the Weather Research and Forecasting (WRF) model (Skamarock et al. 2008). Attributes of forecast rain areas, defined using length and intensity scales consistent with those of mesoscale convective systems (MCSs), revealed the overprediction of the number of rain areas with length scales $\geq 80 \mathrm{~km}$. Additionally, Davis et al. (2006b) defined rain systems by associating rain areas across consecutive 1-h time intervals. For rain systems, the WRF model overpredicted the average duration, and forecast systems typically occurred $1-2 \mathrm{~h}$ later than observed.

MODE has also been used to evaluate convectionallowing forecasts generated by the Center for Analysis and Prediction of Storms (CAPS) in support of the 2009 and 2010 National Oceanic and Atmospheric Administration/Hazardous Weather Testbed (NOAA/ HWT) Spring Forecasting Experiments (Kain et al. 2010a; Jensen et al. 2010; Clark et al. 2012a). Simply overlaying forecast and observed reflectivity objects defined by MODE revealed that forecasts without radar-dataassimilation frequently contained MCSs with an upstream lag relative to forecasts with radar-data-assimilation during the first $0-6 \mathrm{~h}$ of the forecasts. The lag was attributed to the time needed for non-radar-data-assimilating forecasts to spin up MCSs present near-model initialization.

Other studies applying MODE to convectionallowing forecasts include Johnson et al. (2011a,b), in which cluster analyses were performed to evaluate the systematic similarity-dissimilarity of ensemble precipitation forecasts; Johnson and Wang (2012), in which MODE was used to generate and calibrate object-based probabilistic precipitation forecasts; Johnson and Wang (2013), in which MODE was used to compare the skill of convection-allowing ensemble members using the Advanced Research core of the WRF model (ARW) versus that found when using the Nonhydrostatic Mesoscale Model (NMM) dynamics core of the WRF model; and Johnson et al. (2013), which systematically compared the performance of 1- and 4-km grid-spacing forecasts. Finally, Duda and Gallus (2013) used MODE to diagnose the skill of 3-km grid-spacing WRF model simulations at predicting the convective initiation and upscale evolution of convection into MCSs.

Until recently, MODE has only considered twodimensional spatial objects. ${ }^{2}$ However, efforts are on going to incorporate the time dimension into an extension of MODE known as MODE time-domain (hereafter MODE-TD) that will become part of DTC's MET software package (Bullock 2011). In MODE-TD, contiguous regions of grid points exceeding a specified threshold encompassing both space and time are timedomain objects. The addition of time results in a much more powerful diagnostic tool that can provide information on aspects of phenomena over their entire life cycles including longevity, timing of initiation-dissipation, translation speed, and evolution (e.g., growth, decay, changes in maximum intensity, etc.), all of which could not be diagnosed considering the spatial dimension alone.

MODE-TD concepts should have particularly useful applications to convection-allowing forecast systems, because these concepts will provide a framework for evaluating explicitly depicted convective phenomena such as supercells, MCSs, and flash-flood-producing rainfall systems. In fact, several recent studies have demonstrated useful applications of MODE-TD concepts in convection-allowing forecasts. For example, Clark et al. (2012b, 2013) identified time-domain objects in convection-allowing ensemble forecasts of hourly maximum updraft helicity (UH), a diagnostic for measuring rotation in simulated storms (Kain et al. 2008, $2010 \mathrm{~b}$ ), and found that the total length of forecast UH objects was strongly related to the total pathlength of observed tornadoes over 12-30-h forecast periods. Also, Miller and Correia (2012) and Kain et al. (2013) applied a technique for identifying forecast and observed

\footnotetext{
${ }^{2}$ Although Davis et al. (2006b) devised a method for considering the time dimension by associating precipitation objects at adjacent time periods, this is not a built-in functionality of the MODE software.
} 
convective initiation, which was defined as the local time minima within time-domain objects of simulated reflectivity.

The purpose of this study is to apply a beta version of MODE-TD to a set of convection-allowing precipitation forecasts generated during spring 2010 by CAPS in support of the $2010 \mathrm{NOAA} /$ Hazardous Weather Testbed Spring Forecasting Experiment (SFE2010; Clark et al. 2012a). The forecasts are composed of four members of the Storm Scale Ensemble Forecast (SSEF) system (Xue et al. 2010; Kong et al. 2010) identically configured except for their microphysics parameterization. The main goal of this study is to demonstrate new and insightful methods for comparing various aspects of the forecasts and observations that would not be possible without incorporating the time dimension in object identification. Specific characteristics of time-domain objects examined include spatial distribution, duration characteristics, frequency of initiationdissipation, and translation. Comparisons of average forecast and observed time-domain object attributes are emphasized without attempting to match objects from forecasts to observations. The remainder of this study is organized as follows. Section 2 describes the model and observational precipitation datasets and details of MODE-TD. Section 3 contains results, and section 4 contains a summary and discussion.

\section{Data and methodology}

The simulations were initialized at 0000 UTC and integrated $30 \mathrm{~h}$ over a CONUS domain (Fig. 1) with 4-km grid spacing using the ARW model version 3.1.1. Initial and lateral boundary conditions (3-h updates) were from North American Mesoscale (NAM; Rogers et al. 2009) model analyses and forecasts, respectively. Forecasts from all four members were available for 35 dates during spring 2010: 28-30 April; 3-6, 10-14, 17-21, 24-25, 27-28 May; and 1-4, 7-11, 14-18 June. Radial velocity and reflectivity data from up to 140 Weather Surveillance Radar-1988 Dopplers (WSR-88Ds) and other high-resolution observations were assimilated into the NAM analyses using the Advanced Regional Prediction System (ARPS) three-dimensional variational data assimilation (3DVAR; Xue et al. 2003; Gao et al. 2004) data and cloud analysis system (Xue et al. 2003; Hu et al. 2006; Xue et al. 2008). Physics parameterizations included the Mellor-Yamada-Janjić (MYJ; Mellor and Yamada 1982; Janjić 2002) boundary layer scheme, the Noah land surface model (Chen and Dudhia 2001), and the Goddard (Chou and Suarez 1994) shortwave and Rapid Radiative Transfer Model (RRTM; Mlawer et al. 1997) longwave radiation schemes. No cumulus

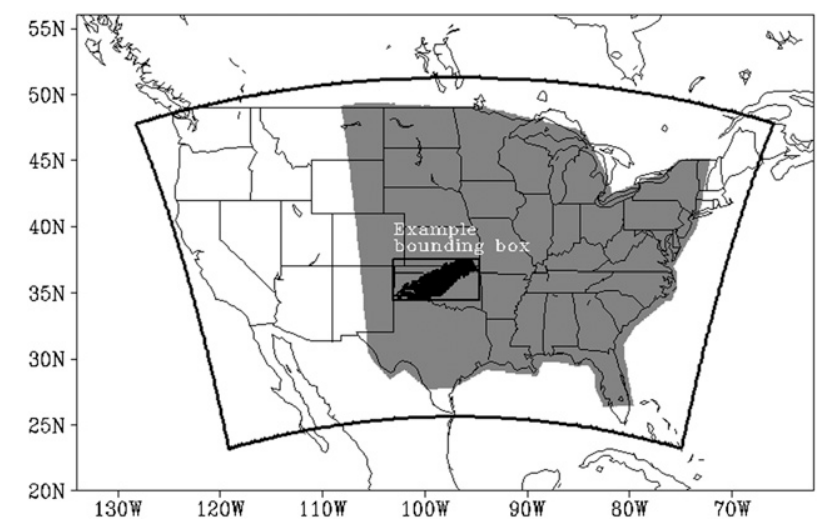

FIG. 1. WRF model domain (black outline) and mask (gray shading) within which forecast and observed time-domain objects were analyzed. The black-shaded area within the gray mask is the area covered by an example time-domain object along with its corresponding bounding box.

parameterization was used. As previously noted, the four particular members examined in this paper differed only by their microphysics parameterizations, which included Thompson et al. (2004), WRF single-moment six-class (WSM6; Hong and Lim 2006), WRF doublemoment six-class (WDM6; Lim and Hong 2010), and Morrison et al. (2005).

We chose the varied-microphysics members for MODE-TD analyses because there were a reasonable number of members to allow for thorough but not overwhelming statistical analysis of time-domain object attributes. Furthermore, there is strong scientific interest in examining different microphysics parameterizations in high-resolution models, especially the two "double moment" schemes, WDM6 and Morrison, which were newly available in WRF version 3.1.1. Double-moment schemes contain prognostic equations for both mixing ratios and number concentrations of certain hydrometeor species, unlike single-moment schemes, which only contain prognostic equations for mixing ratios. Recent work indicates that double-moment schemes are necessary for reproducing dual-polarization signatures in ensemble Kalman filter analyses of supercells (Jung et al. 2012) and MCSs (Putnam et al. 2014). Additionally, Dawson et al. (2010) obtained more accurate simulations of a tornadic supercell with two- and three-moment schemes, especially with the simulated cold pool. Comparing idealized simulations, Bryan and Morrison (2012) found that a double-moment scheme produced a more realistic depiction of a squall line than a single-moment scheme. On the other hand, there has yet to be work showing a distinct advantage to using double-moment over single-moment schemes in convection-allowing simulations for forecast lead times between 12 and $36 \mathrm{~h}$ (e.g., Clark et al. 2012a). 
During SFE2010, one daily model evaluation activity involved subjectively examining simulated composite reflectivity forecasts from the four varied-microphysics members (Clark et al. 2012a). One interesting result was that, in the latter portions of the 30-h forecasts, the nonThompson schemes tended to generate stronger (i.e., colder) cold pools and associated MCSs that propagated too quickly toward the east and/or south, while the Thompson forecasts had weaker, more realistic cold pools relative to the non-Thompson members that were associated with smaller MCS displacement errors. Thus, one goal of this study is to examine whether these differences are reflected in average time-domain object translation speeds. For the verification dataset, the National Centers for Environmental Prediction (NCEP) stage IV (Baldwin and Mitchell 1997) multisensor rainfall estimates were used. The 4-km stage IV grids were remapped onto the 4-km model grid using a neighborbudget interpolation (e.g., Accadia et al. 2003).

Identifying objects in MODE-TD involves a smoothing and thresholding step as in traditional MODE, but with the added time dimension. First, hourly precipitation fields are smoothed by taking a simple average of the precipitation at all grid points within a specified radius of influence of each grid point. The appropriate value for the smoothing radius is application dependent and user defined. The main purpose of smoothing is to make areas of rainfall more contiguous than in the original field, as well as to filter out small or weak precipitation objects the user is not interested in (Davis et al. 2009). The thresholding step involves creating a binary mask where grid points that do not exceed the minimum value for object classification are set to zero, which allows object boundaries to be detected. After thresholding, each contiguous region of nonzero grid points in space and time is considered a separate object, and the grid points within each object are assigned a unique nonzero integer. For any particular point, contiguous points include those that are immediately adjacent in space, as well as those at the nearest previous and subsequent times that either overlap or are immediately adjacent in space. Because this study only examines average object attributes, fuzzy-logic-based algorithms for matching-merging forecast and observed objects were not applied.

MODE-TD was applied to forecast and observed hourly precipitation fields using smoothing radii of 8,16 , and $32 \mathrm{~km}$, as well as precipitation thresholds of 0.10 - and 0.25 -in. $(1 \mathrm{in} .=2.54 \mathrm{~cm})$, yielding six unique combinations of parameters. Additionally, objects were required to contain at least 10 grid points. Finally, the entire area of each forecast and observed time-domain object "bounding box" was required to fall within the mask pictured in Fig. 1.
The bounding box of an object is the rectangular area created using the farthest west and south point within the object as the lower-left corner and the farthest north and east point as the upper-right corner. An example bounding box and the area covered by its corresponding time-domain object are also shown in Fig. 1. The mask was constructed to encompass regions over which the stage IV observations were most reliable (i.e., east of the Rockies, within the United States, and over land). The smoothing radii chosen represent a range of scales near the lower bound of what the simulations can resolve and, when combined with the precipitation thresholds that were chosen, effectively capture precipitation associated with organized MCSs as well as smaller and shorter-duration convective storms. Using the smallest radii and precipitation thresholds retains many of the smaller and shorter-duration precipitation objects along with the more intense MCSs, while the largest ones mainly only retain objects associated with organized MCSs. The criterion that the objects contain at least 10 grid points was imposed so that only objects approximately large enough to be easily identifiable by a human would be retained.

For each time-domain object identified by MODETD, 69 attributes were computed $(i, j$, and $t$ refer to eastwest, north-south, and time model grid coordinates, respectively): 1) the object volume (total number of grid points within an object);2-4) $i, j$, and $t$ centroid coordinates, respectively; 5) minimum $i$;6) maximum $i$; 7) minimum $j ; 8$ ) maximum $j$;9) minimum $t$;10) maximum $t$; 11) ratio of object volume to bounding-box volume, where the bounding box is defined using the maximumminimum $i, j$, and $t$ coordinates; 12$) u$-velocity component at forecast hour 2 [i.e., $\left(i\right.$-centroid ${ }_{t=2}-i$-centroid - $\left._{t=1}\right) /$ $1 \mathrm{~h}$ ]; 13) $v$-velocity component at forecast hour 2 [i.e., $\left(j\right.$-centroid t $_{t=2}-j$-centroid - $\left.\left._{t=1}\right) / 1 \mathrm{~h}\right]$; 14) $u$-velocity component at forecast hour 3 [i.e., $\left(i\right.$-centroid ${ }_{t=3}-i$-centroid $\left.{ }_{t=2}\right) /$ $1 \mathrm{~h}$; 15) $v$-velocity component at forecast hour 3 [i.e., $\left(j\right.$-centroid te $_{t=3}-j$-centroid - $\left.\left.\left._{t=2}\right) / 1 \mathrm{~h}\right], \ldots, 68\right) u$-velocity component at forecast hour 30 [i.e., $\left(i\right.$-centroid $_{t=30}-$ $i$-centroid - $\left.\left._{t=29}\right) / 1 \mathrm{~h}\right]$, and 69) $v$-velocity component at forecast hour 30 [i.e., $\left(j\right.$-centroid ${ }_{t=30}-j$-centroid $\left.{ }_{t=29}\right) /$ $1 \mathrm{~h}]$. For the first hour an object was present and when the object did not exist, missing values of -9999.0 were assigned to the $u$ - and $v$-velocity components. Centroid coordinates were computed using the mean $i, j$, and $t$ over the object volume.

\section{Results}

\section{a. MODE-TD example}

Figure 2 shows example time-domain precipitation objects from the four microphysics parameterizations 

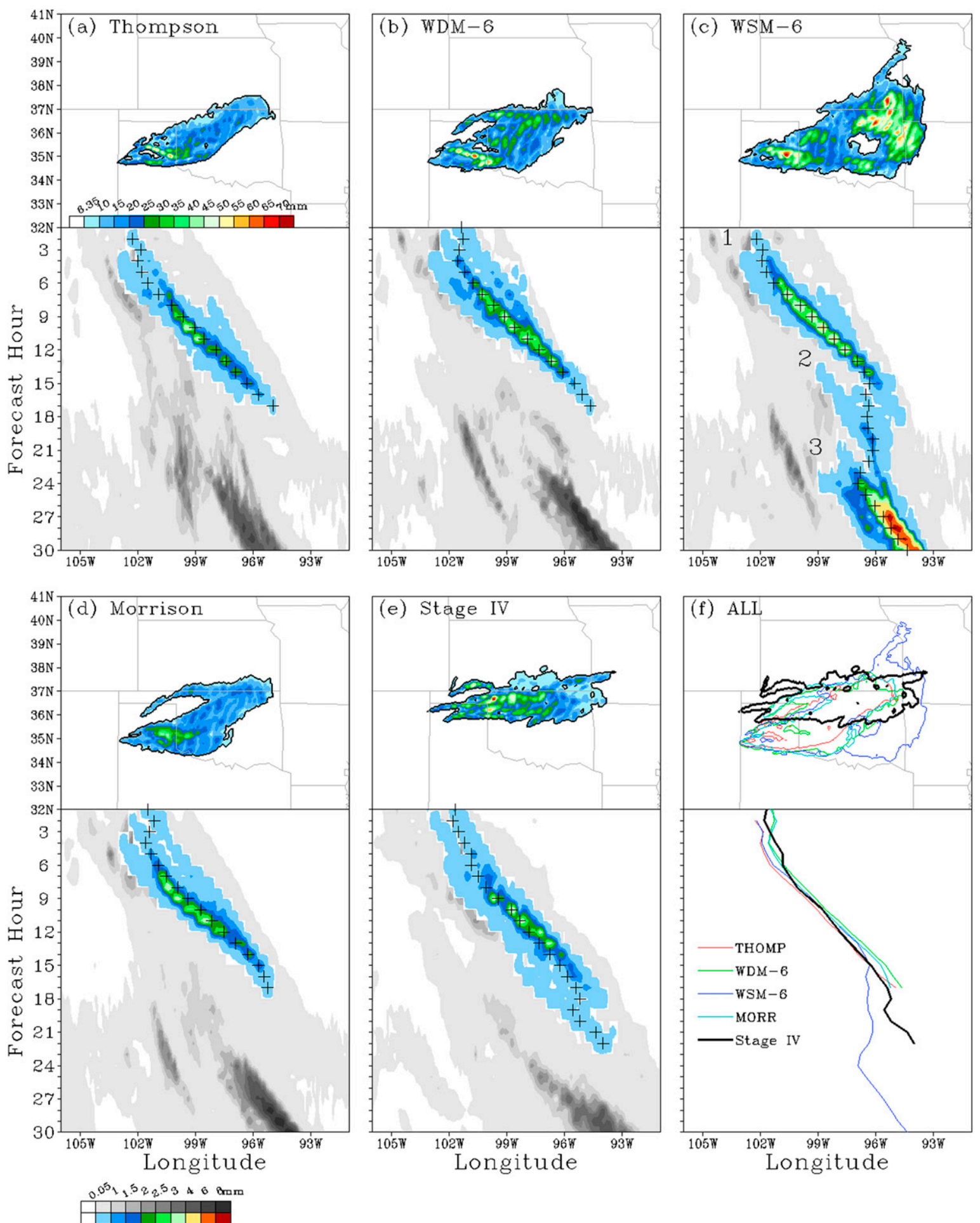

FIG. 2. Example time-domain precipitation objects defined using a threshold of $0.25 \mathrm{in}$. and a smoothing radius of $8 \mathrm{~km}$ for WRF model simulations initialized at 0000 UTC 19 May 2010 using (a) Thompson, (b) WDM6, (c) WSM6, and (d) Morrison microphysics parameterizations. (e) Shows the stage IV observations. Each top panel shows the maximum precipitation (mm) over the lifetime of the object and bottom ones show the time-longitude diagrams of the corresponding precipitation object indicated by colored shading with the plus signs (+) marking the centroid longitudes at each time the object was present. The black-gray-white shading is for precipitation not included in the object. A color bar for the spatial plots is provided in (a) and color bars for the time-longitude plots are below (d). In (c), the labels 1, 2, and 3 denote three distinct rainfall systems composing the single time-domain object (discussed in the text). (f) The outer object contours for each simulation and observations are overlaid in the top panel. In the bottom panel, the lines indicate paths of model and observed object centroids in time-longitude space with a legend provided to the left. 


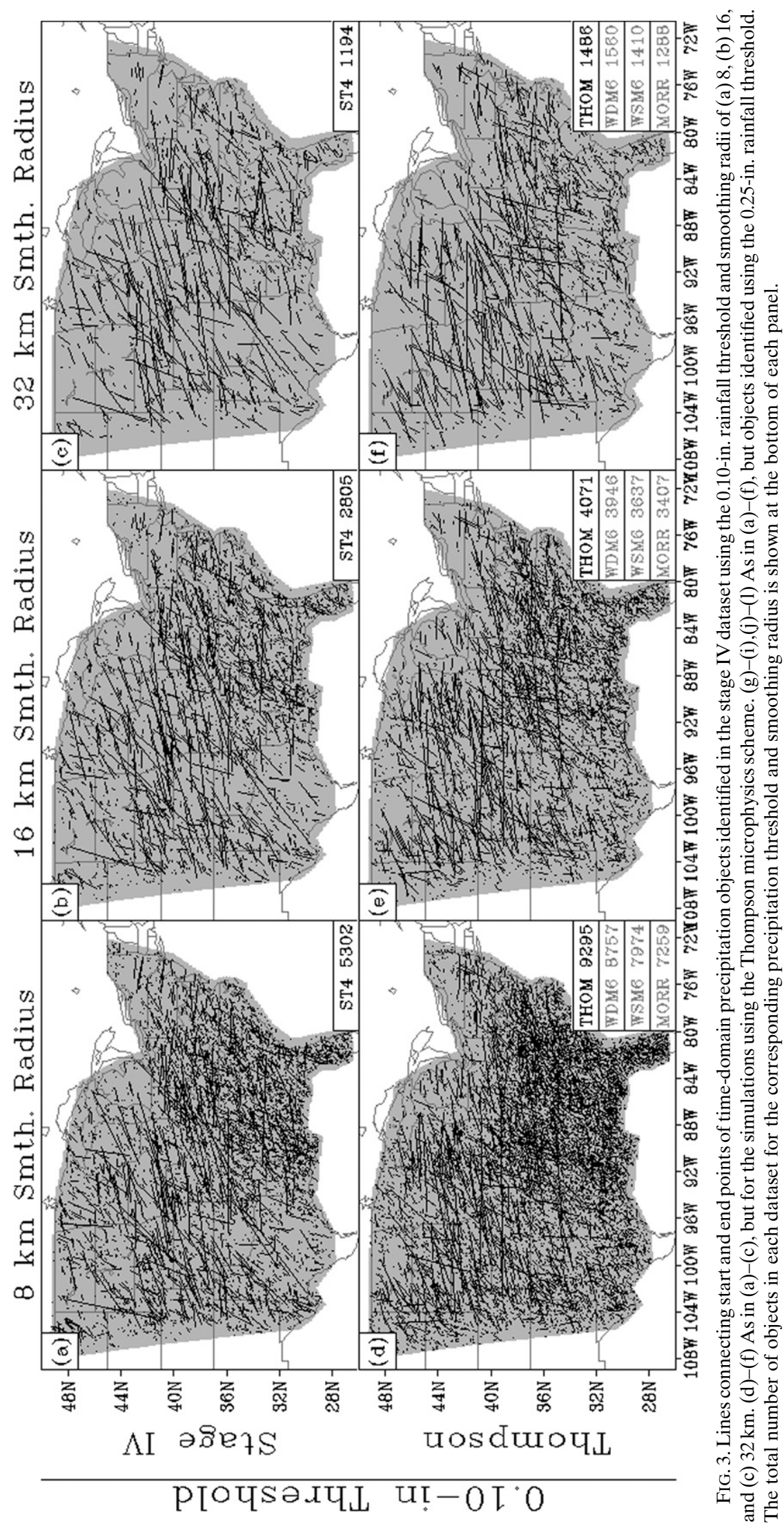




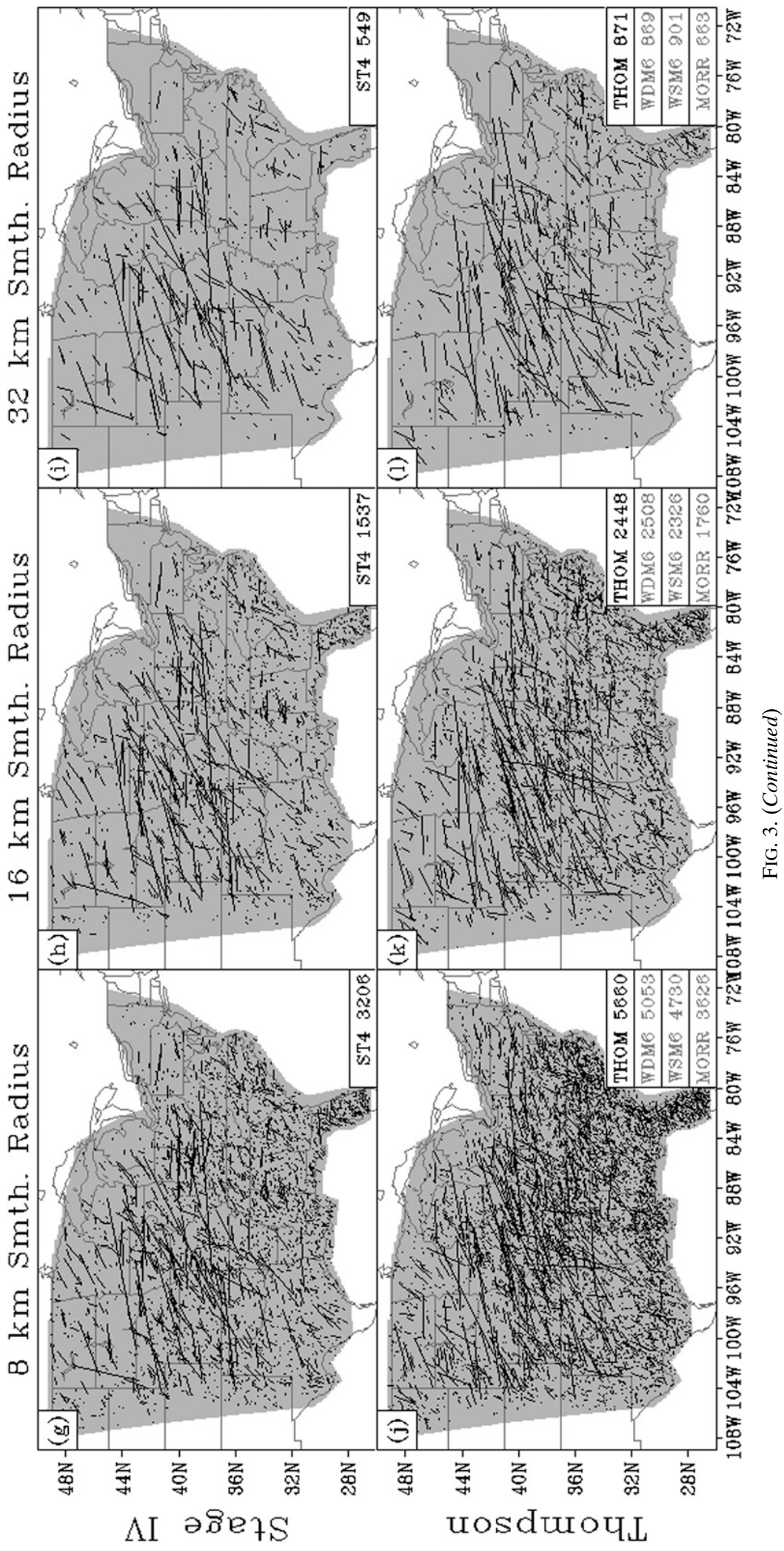

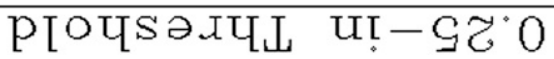




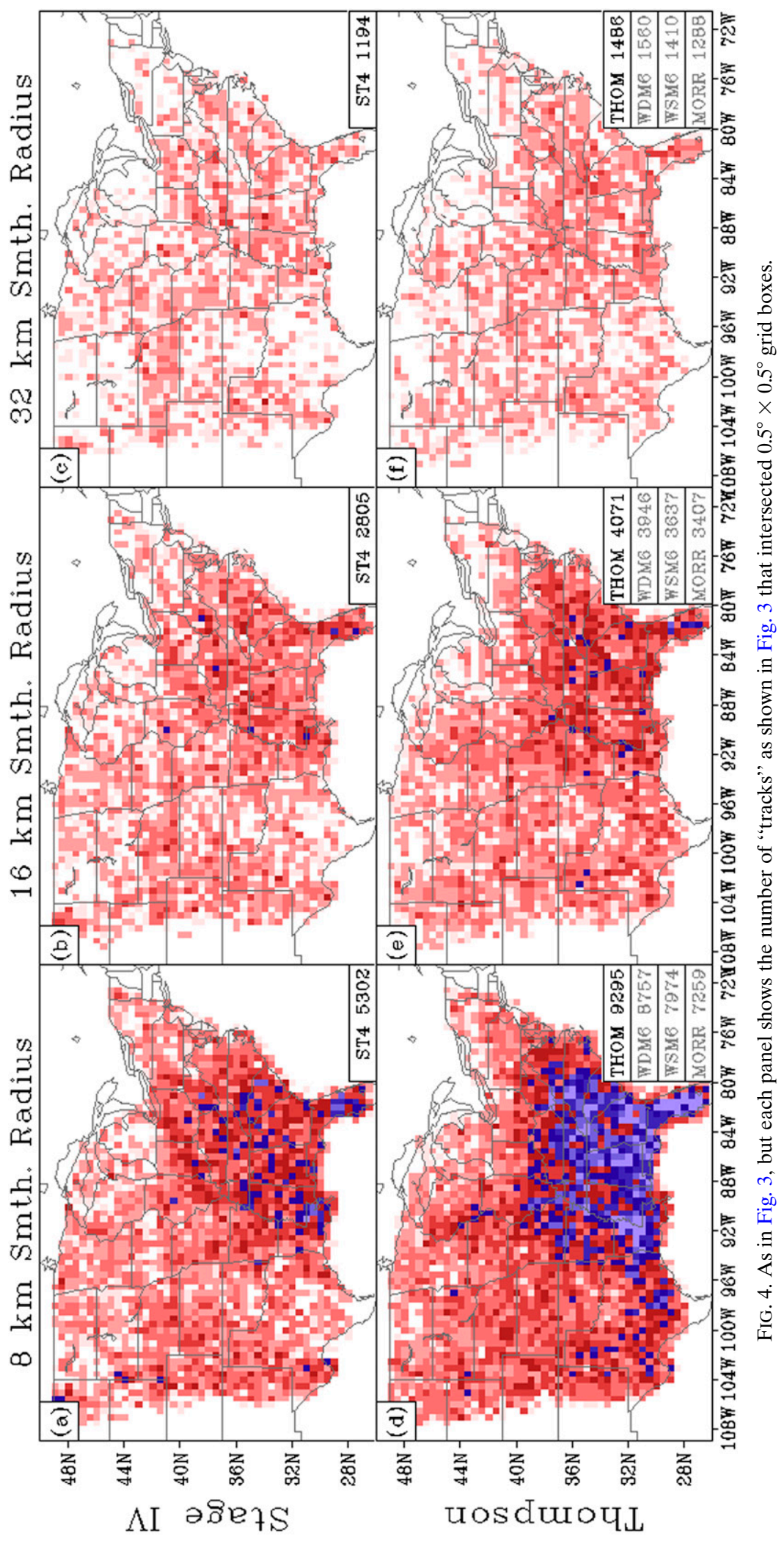

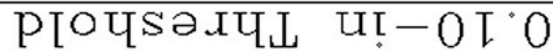




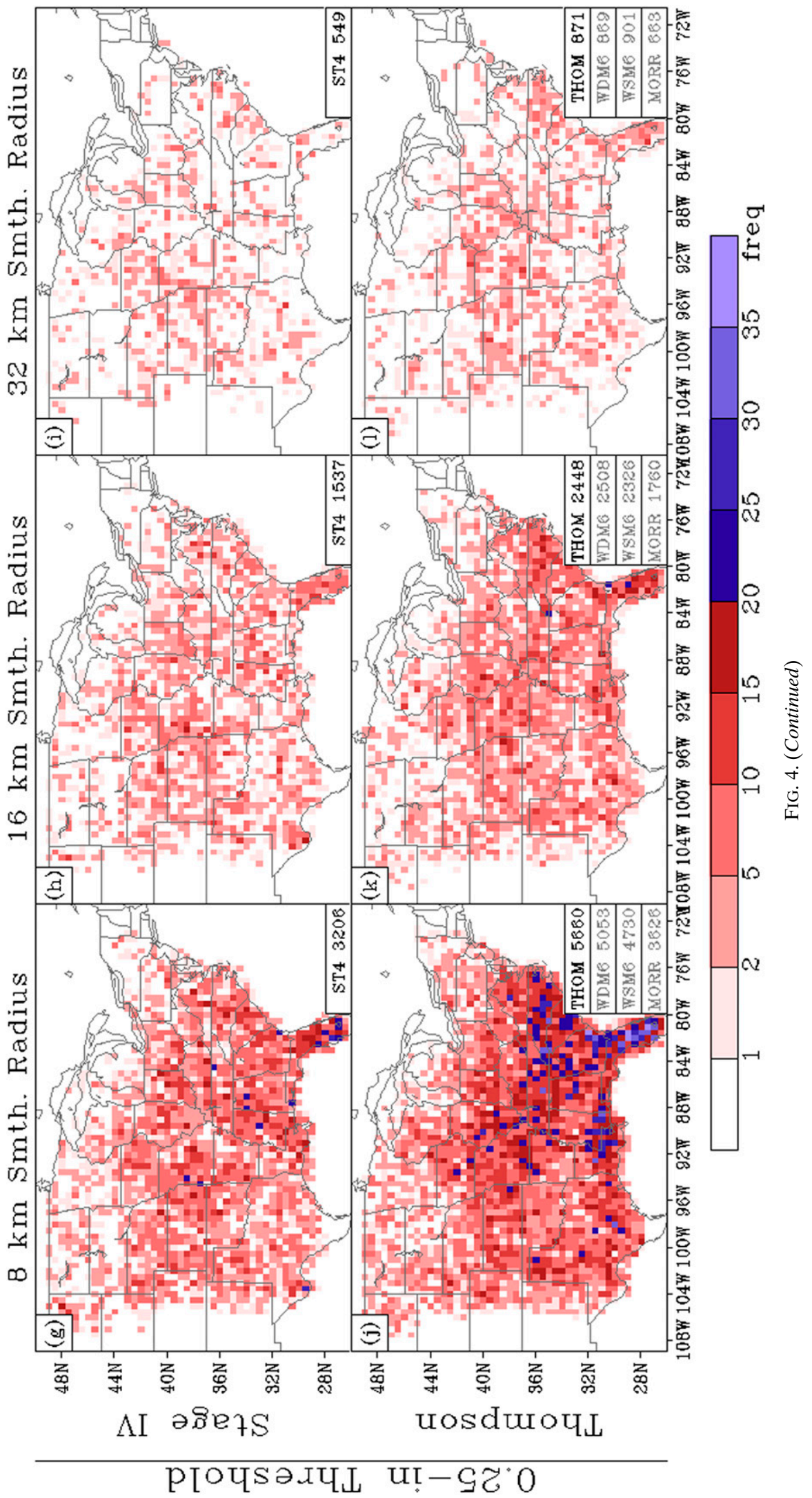


and stage IV observations for a long-lived MCS that occurred on 19 May 2010 over Texas and Oklahoma. At the top of each panel in Fig. 2, the maximum value of precipitation at each $i, j$ point over the lifetime of the object is shown, and at the bottom, time-longitude plots (latitudinally averaged) illustrate the zonal translation of the objects. The objects depicted by Thompson (Fig. 2a), WDM6 (Fig. 2b), and Morrison (Fig. 2d) each have a duration of about $17 \mathrm{~h}$, while the stage IV object (Fig. 2e) has a duration of about $22 \mathrm{~h}$. The object in WSM6 (Fig. 2c) is noticeably different, as it lasts for the entire 30-h forecast period. However, the long duration for the WSM6 object was not the result of a single rainfall system. Rather three clearly distinct rainfall systems translating west to east happened to be "connected" in space and time, composing a single time-domain object. The approximate initiation times and locations for each of these distinct systems are marked 1, 2, and 3 in Fig. 2c. In such a case of merging precipitation systems, the velocity components can be inconsistent with the movement of the individual systems composing the single time-domain object because the velocity calculations consider all grid points within the object at each time regardless of whether these points are from separate systems. For example, system 2 in Fig. 2c is clearly translating west to east during the 14-23-h forecast period, but the object centroids remain at about the same longitude because they are influenced by the grid points of systems 1 and 3, which are also present during these times. This type of problem is fairly common in object-based applications and in the future could be alleviated by applying more complex image-processing algorithms like watershed transforms (e.g., Lakshmanan et al. 2009), which can separate single objects into distinct regions based on their spatial patterns. Separation of the objects would increase the object frequencies and result in an improved depiction of the translation speeds for individual objects. However, to the best of our knowledge, there is not a tendency for any particular microphysics parameterization to exhibit these distinctly different but connected objects more than the other schemes; thus, we do not believe there is any systematic impact on the comparisons presented in subsequent sections.

\section{b. Spatial distribution of time-domain objects}

Locations of precipitation object tracks over the entire 35-day analysis period are shown by lines connecting object centroids at their first and last time for Thompson and stage IV observations in Fig. 3, and object track frequencies within $0.5^{\circ} \times 0.5^{\circ}$ latitude-longitude grid boxes are shown in Fig. 4. The non-Thompson schemes are not shown to simplify the plots, but their spatial distributions of object tracks were very similar to those of Thompson. In the simulations and observations, the total number of tracks (indicated at bottom right of each panel in Figs. 3 and 4) decreases with increasing smoothing radius. For example, in stage IV objects identified using the 0.10 -in. rainfall threshold (Figs. 3a-c), the total numbers of objects are 5302, 2805, and 1194, for 8-, 16-, and 32-km smoothing radii, respectively. This reduction is consistent with smoothing reducing the precipitation amplitude so that fewer areas reach the criteria for object classification. Additionally, smoothing can cause closely separated areas of precipitation to combine into one, further reducing object numbers. On the other hand, in certain cases smoothing could increase the number of objects. For example, consider one object composed of two areas of relatively heavy precipitation separated by light-moderate precipitation. If smoothing damps the amplitude of the light-moderate precipitation enough so that it falls below the threshold required for object classification, the two areas of heavy precipitation would no longer be "connected" and would thus compose two separate time-domain objects.

The different smoothing radii also impact the spatial distribution of object tracks. For the smallest radius, in simulations and observations there is a clear maximum in object frequencies over the southeast United States (e.g., Figs. 4a,d,g,j). However, as the smoothing radius increases, the southeast U.S. maximum disappears and the spatial distribution of objects becomes quite uniform. The reduction over the southeast United States implies that, although precipitation may be more frequent, objects here tend to be smaller, shorter lived, and less intense than those over other regions and thus more easily filtered out by a large smoothing radius. This behavior is consistent with the precipitation climatology over the southeast United States during spring and summer when short-lived thunderstorms driven by diurnal heating are common. Furthermore, at the largest smoothing radius and in particular for time-domain objects identified using the 0.25 -in. precipitation threshold (Figs. 3i,l), there is a broad region of the central United States roughly centered over Iowa, Nebraska, Kansas, Missouri, and Illinois, where relatively long object tracks are concentrated. These long tracks likely reflect long-lived MCSs, which are climatologically favored over this west-east corridor during the spring and summer (e.g., Ahijevych et al. 2004; Tuttle and Davis 2006).

At all thresholds and smoothing radii, all four microphysics parameterizations overpredict the total number of time-domain objects. This result is not surprising as the tendency for convection-allowing models to overpredict precipitation is well documented (e.g., Schwartz 
et al. 2010; Clark et al. 2009; Skamarock and Weisman 2009), and Johnson and Wang (2013) and Johnson et al. (2013) also found substantial overprediction of objects in convection-allowing forecasts. Generally, Thompson overpredicts the most, while Morrison overpredicts the least.

\section{c. Object duration statistics}

Object number as a function of duration for each threshold and smoothing radii is shown in Figs. 5a-c and $5 \mathrm{~g}-\mathrm{i}$. Additionally, to eliminate the impact of overprediction on the shape of the distributions, the object numbers for each duration were normalized by the total number of objects for each threshold-radius (Figs. 5d-f and $\mathrm{j}-1)$. For the 0.10 -in. rainfall threshold and the $8-\mathrm{km}$ smoothing radius (Fig. 5a), the number of objects in the models and observations peak at 3-h duration and then quickly tail off for longer durations. The overprediction of object numbers is apparent as well, with the peak at $3 \mathrm{~h}$ in the Thompson and WDM6 schemes almost twice that of the stage IV observations. However, considering the normalized object frequencies, all the simulations replicate the shape of the observed distribution well (Fig. 5d).

As the smoothing radius is increased to $32 \mathrm{~km}$ at the 0.10 -in. threshold, the peak in stage IV frequencies shifts to 2-h duration (Fig. 5c). Furthermore, as can be seen by examining the normalized plots (Figs. $5 \mathrm{~d}-\mathrm{f}$ ), as the smoothing radius increases, the amplitude of the peak decreases and the distributions broaden in both the simulations and stage IV observations. Also, while the peak is clearly at 2-h duration for stage IV with the $32-\mathrm{km}$ smoothing radius, the peak in WDM6 is at 3-h duration. For the 0.25 -in. rainfall threshold, the patterns of behavior of the simulations and observations are similar to that from the 0.10 -in. threshold. However, there is a more dramatic shift in peak object frequencies to shorter durations with increasing smoothing radius. In the stage IV dataset, $1 \mathrm{~h}$ is the most frequent object duration using the 32-km smoothing radius and there is a notable discrepancy with Thompson, WDM6, and WSM6, which have peak durations of 2 or $3 \mathrm{~h}$. At the 0.25-in. threshold, Morrison stands out for matching the stage IV distributions much better than the other schemes, in particular, using a $16-\mathrm{km}$ smoothing radius (Figs. 5h,k). The shift to shorter object durations with increasing smoothing radius results from the increased smoothing dampening the precipitation magnitudes. Thus, when using a small smoothing radius, times within an object with relatively light precipitation may be completely removed when using a larger smoothing radius. If these times occur at the beginning or end of the object lifetime, the object duration will be shortened, and if they occur within the middle of the object lifetime (e.g., object with two precipitation peaks), the object will be split into two shorter-duration objects. It is likely that the peak object frequencies at the highest smoothing radius and rainfall threshold in the Thompson, WDM6, and WSM6 simulations do not match well with observations because their precipitation objects are too intense. Thus, there are fewer times at which a portion of the objects are eliminated by a larger smoothing radius.

\section{d. Diurnal cycle of object frequencies}

The total number of time-domain objects present at each forecast hour identified using the 0.10 -in. threshold and $8-\mathrm{km}$ smoothing radius is shown in Figs. 6a-d. Because MODE-TD provides object start and end times, it is also possible to separate the objects present at each forecast hour according to the hour at which the objects initiated. Thus, at each hour in Figs. 6a-d, the height of individual segments composing each histogram bar indicate the number of objects initiating at a specific forecast hour, with the color of the segments indicating the hour the objects originated. For example, at forecast hour 21 in Figs. 6a-d, the top segment colored dark red indicates the number of observed objects that initiated at that hour. The white segment immediately below indicates the number of observed objects that initiated the previous hour (forecast hour 20) and still present at hour 21. The light pink segment below the white segment indicates objects initiating $2 \mathrm{~h}$ before (i.e., forecast hour 19 ) and still present at hour 21, and so on. The segments are stacked so that the most recent forecast hour is always on top and forecast hour 1 is always at the bottom. This pattern allows one to follow segments with a particular color forward in time to visualize how quickly objects initiating from a particular hour dissipate. For example, following the dark red color forward in time corresponding to observed objects initiating at forecast hour 1 , it is apparent that these objects have mostly dissipated by forecast hour 12 .

Generally, for the 0.10-in. rainfall threshold and 8-km smoothing radius, the simulations depict the shape of the diurnal cycle in object frequencies quite well, with a gradual decrease from a relative peak at the initial hour to a relative minimum between forecast hours 9 and 14 , followed by a sharp increase to a peak at forecast hours 21 and 22. However, consistent with previous results, the simulations overpredict object frequencies quite uniformly across all hours, with Thompson overpredicting the most and Morrison the least, which is most apparent when comparing the magnitude of the forecast hour 21-22 peak.

The frequency of object initiation and dissipation can also be computed and is shown in Figs. 6e and 6f, 

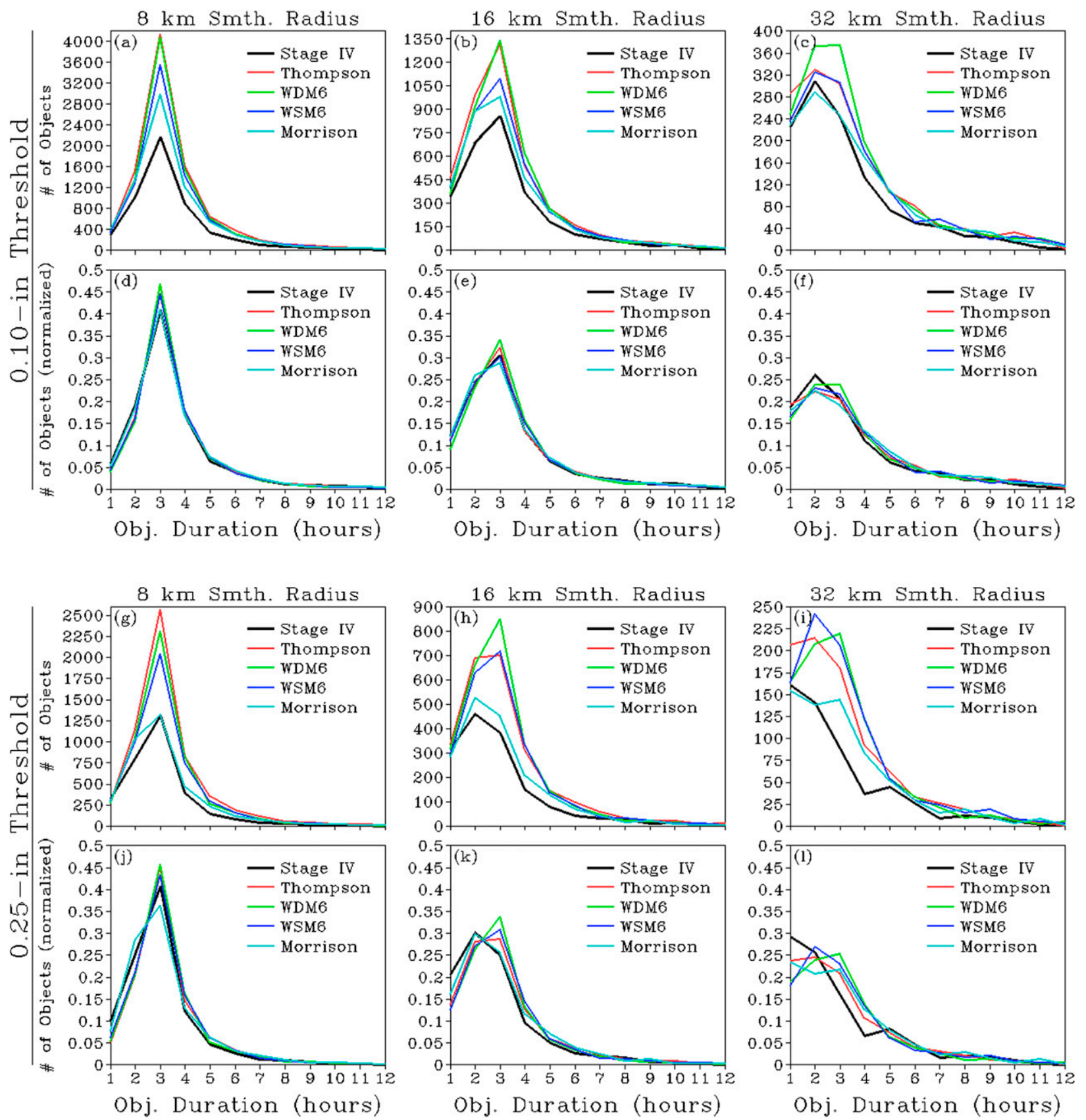

FIG. 5. The number of time-domain precipitation objects as a function of duration $(\mathrm{h})$ in forecasts and corresponding observations using the 0.10-in. rainfall threshold and smoothing radii of (a) 8, (b) 16 , and (c) $32 \mathrm{~km}$. (d)-(f) As in (a)-(c), but the number of objects at each duration for each dataset is normalized by the total number of objects across all durations in each dataset. (g)-(i), (j)-(l) As in (a)-(c), (d)-(f), respectively, but the objects are identified using the 0.25 -in. rainfall threshold.

respectively. Consideration of initiating-dissipating object frequencies is important because they control the rate of change in the object numbers at a particular forecast hour [i.e. more (less) initiating relative to dissipating objects results in an increase (decrease) in total objects]. The number of initiating objects is simply defined as the number of objects with their first time at a given forecast hour. In Figs. 6a-d, the number of initiating objects at each hour is indicated by the height of the top bar in each set of stacked histograms. ${ }^{3}$ The

\footnotetext{
${ }^{3}$ Time-domain objects with their start time at forecast hour 1 are not counted as "initiating" objects because most of these objects would have actually initiated before the model initialization.
} 

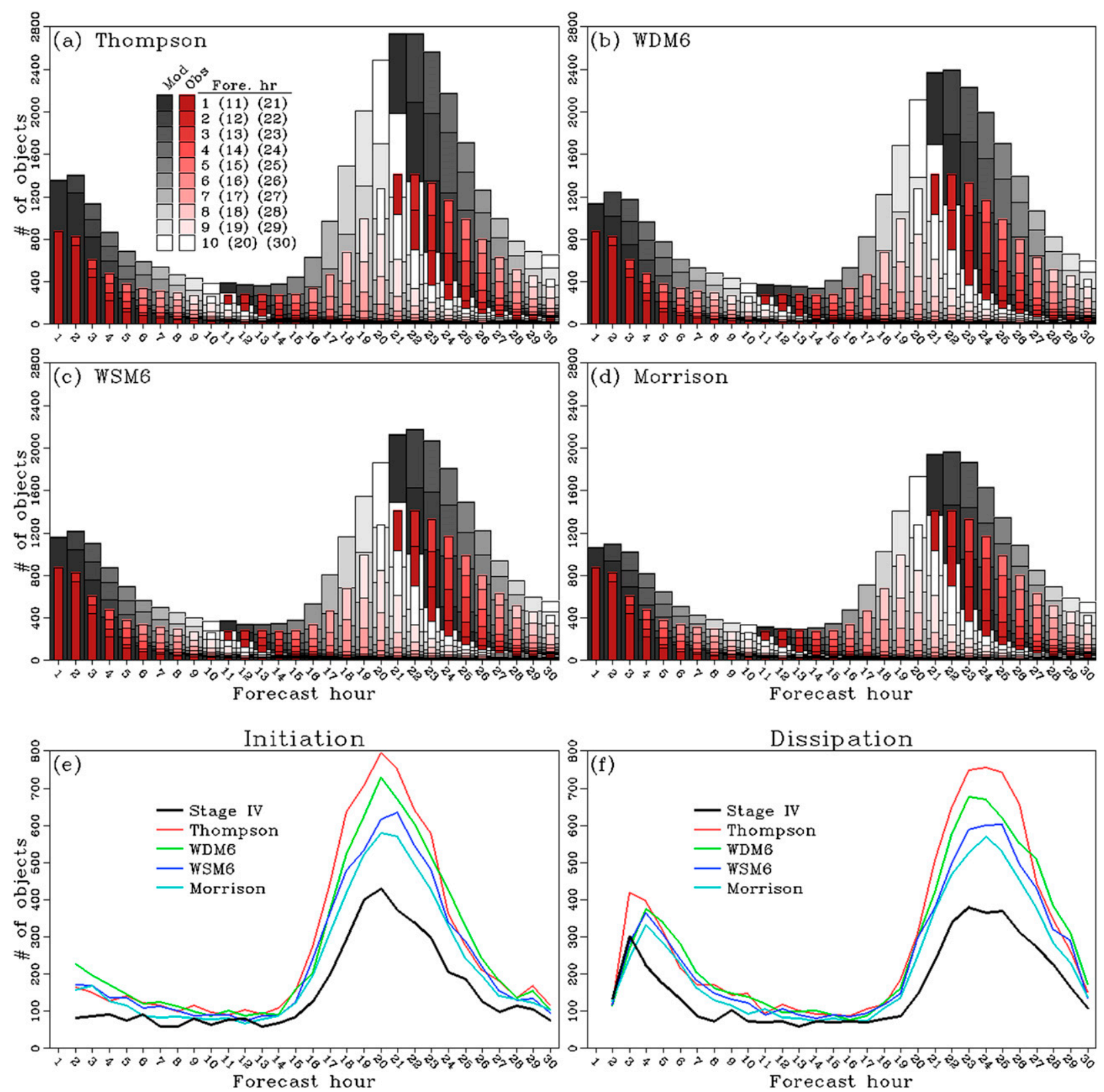

FIG. 6. The height of the stacked histogram bars indicates the total number of time-domain precipitation objects at each forecast hour identified using the 0.10-in. rainfall threshold and 8-km smoothing radius for (a) Thompson, (b) WDM6, (c) WSM6, and (d) Morrison. In (a)-(d), histogram bars for the stage IV objects are shaded pink to red and overlaid on those of the model, which are shaded white to black. For each forecast hour along the $x$ axis, the height of the individual segments composing each "stack" indicates the number of objects originating during the forecast hour as marked by the color of the segment. The segments on top always indicate the number of objects that initiated at the marked forecast hour and those on the bottom are always for forecast hour 1. A legend for the colored histogram bars is provided in (a). (e),(f) The number of objects that initiated and dissipated, respectively, at each forecast hour (explained further in text).

number of dissipating objects at a particular forecast hour is defined as the number of objects from the previous hour no longer present.

For the stage IV observations, the number of initiating objects remains nearly constant between forecast hours 2 through 15 , begins increasing at forecast hour 16 , reaches a peak at forecast hour 20 , and then decreases until flattening again at about forecast hour 27 (Fig. 6e). The peak in initiating objects lags the peak in total objects by about $1-2 \mathrm{~h}$ because the number of dissipating objects remains less than the number of initiating ones until about forecast hour 22. In the simulations, the shape of the diurnal cycle in initiating objects is similar to that of the stage IV observations. However, instead of a relatively 

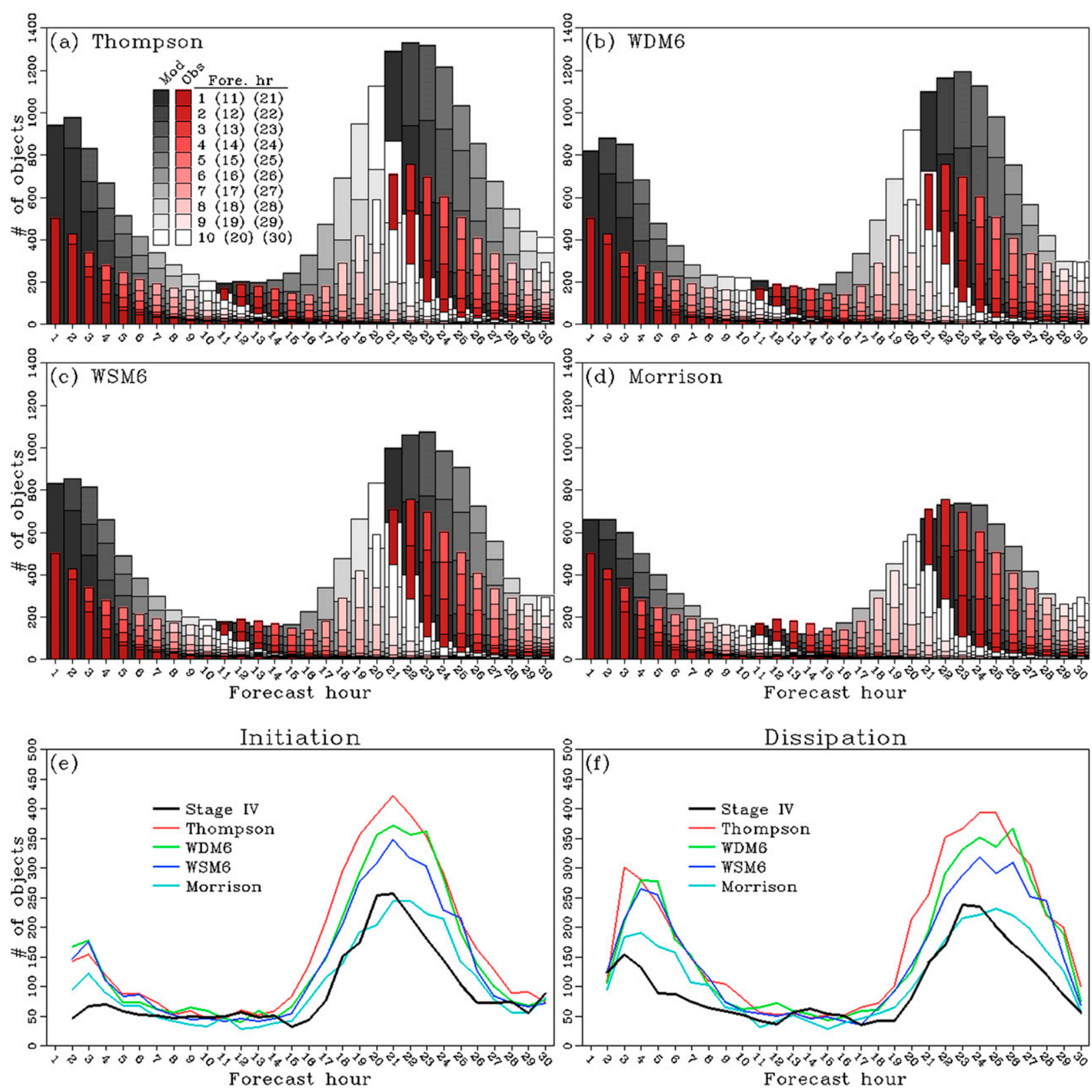

FIG. 7. As in Fig. 6, but for the 0.25-in. rainfall threshold and 8-km smoothing radius.

constant number of initiating objects between forecast hours 2 and 15, there is a gradual decrease in the simulations. Additionally, although the peak in initiating objects in the simulations occurs at about the same time as the stage IV observations, the amplitude of the peak is too high in the simulations.

The pattern in the diurnal cycle of dissipating objects for the simulations and stage IV observations (Fig. 6f) generally follows that of initiating objects, except there is a small maximum in dissipating objects near the beginning of the forecast period and the maximum near forecast hour 24 lags that of initiating objects by about 3-4h. The 3-4-h lag between initiating and dissipating object frequencies is consistent with the peak in observed and simulated object lifetimes at the 0.10-in. threshold and 8-km smoothing radius of $3 \mathrm{~h}$ (Fig. 5a).

The object frequencies for the same 8-km smoothing radius as in Fig. 6, but for a higher rainfall threshold of 0.25-in., are shown in Fig. 7. In the observations, peak object frequencies occur at forecast hour 22, which is $1 \mathrm{~h}$ later compared to the 0.10 -in. rainfall threshold. Additionally, the observations have a small peak at forecast hour 12 , which likely reflects the semidiurnal signal, as discussed by Carbone et al. (2002). Similar to the 0.10-in. 
threshold, the simulations depict the general pattern of the diurnal cycle in object frequencies for the 0.25 -in. threshold quite well. However, the overprediction during the first $6 \mathrm{~h}$ of the forecast is more dramatic than at the 0.10 -in. threshold for all four simulations, which is likely simply related to these simulations having a higher bias at the larger rainfall thresholds during the peaks in the diurnal cycle. Also, in WDM6, WSM6, and Morrison (Figs. 7b-d), the peak object frequencies occur at forecast hour 23, which is $1 \mathrm{~h}$ later than the stage IV observations, while the peak frequencies in Thompson (Fig. 7a) are the same as those for stage IV. The amplitude of the afternoon-evening peak is overpredicted in Thompson, WDM6, and WSM6, but in Morrison the amplitude is very close to that of the stage IV observations. None of the simulations has as clear of a semidiurnal peak at forecast hour 12 as the stage IV observations, but Thompson and Morrison at least have $1 \mathrm{~h}$ near or at forecast hour 12 with slightly higher object frequencies than adjacent hours.

For the frequencies of initiating objects (Fig. 7e), the pattern in stage IV observations is again quite similar to that from the 0.10 -in. threshold, but the peak for $0.25 \mathrm{in}$. occurs at forecast hour 21 , which is $1 \mathrm{~h}$ later than the peak using the 0.10 -in. threshold. In the simulations, the initiating object frequencies are too high at the start of the forecast period, but gradually decrease and approximately fall in line with the observations by about forecast hour 8 . Similar to the peak in total object frequencies, all simulations except for Morrison overpredict the peak in initiating object frequencies. Also, the timing of the peak in initiating object frequencies from the simulations matches that of the observations.

For the dissipating object frequencies at the 0.25-in. threshold and 8-km smoothing radius (Fig. 7f), the simulations have a noticeable peak at forecast hours 3 and 4 that is not nearly as pronounced in the stage IV observations. This peak reflects the dissipation of objects that were overpredicted during the first $1-2 \mathrm{~h}$ of the simulations. Furthermore, for the late afternoonevening peak in dissipating objects, the peak in the simulations occurs $1-2 \mathrm{~h}$ later than in the observations, which is consistent with the peak in total object frequencies from the simulations occurring about $1-2 \mathrm{~h}$ later relative to the observations.

To examine the impact of increased smoothing radii on the diurnal object frequencies, Figs. 8 and 9 are the same as Figs. 6 and 7, respectively, but for a smoothing radius of $16 \mathrm{~km}$ instead of $8 \mathrm{~km}$. For the 0.10 -in. threshold (Fig. 8), the afternoon-evening peak in the stage IV observations occurs at forecast hour 22 , which is $1 \mathrm{~h}$ later than the observed peak using an 8-km smoothing radius. This shift in the peak suggests that the increased smoothing eliminates more times at the beginning of an object's lifetime than at the end, which would occur given an asymmetric evolution in intensity with time (i.e., objects reach peak intensity after the midpoint in their lifetime). The relative amount of overprediction in the object frequencies from the simulations is less when using the $16-\mathrm{km}$ smoothing radius compared to the $8-\mathrm{km}$ radius. In fact, the Morrison simulation in particular has a pattern and amplitude in object frequencies that matches the stage IV observations very well (Fig. 8d). Similarly, for frequencies of initiating and dissipating objects, the overprediction is not as dramatic when using the $16-\mathrm{km}$ smoothing radius compared to the $8-\mathrm{km}$ smoothing radius. The timing of the peak initiatingdissipating object frequencies in the simulations is generally within $1 \mathrm{~h}$ of the observations.

For the 0.25 -in. rainfall threshold and 16-km smoothing radius (Fig. 9), the peak in stage IV object frequencies during the afternoon-evening occurs at forecast hour 22, which is the same as that using the 8-km smoothing radius. However, in the Thompson, WSM6, and Morrison simulations the peak shifts $1-2 \mathrm{~h}$ later compared to the peak using the $8-\mathrm{km}$ smoothing radius, so that the peak in these simulations lags that of the observations by $2 \mathrm{~h}$. For WDM6, the timing of the peak lags the observations by $1 \mathrm{~h}$. For the frequencies of initiating objects (Fig. 9e), the behavior in the simulations is similar to the previously discussed plots, but for dissipating objects the spurious peak in the simulations near forecast hour 4 is more dramatic.

\section{e. Time-domain object velocities}

The $u$ and $v$ components as well as the total speed (velocity magnitude) of the objects are shown as a function of forecast hour in Fig. 10. At each hour, average velocity components are computed over all the objects that were present and had valid velocity components. ${ }^{4}$ Additionally, at each hour, the distribution of velocities in each of the simulations was compared to that of the observations to determine whether the difference in means was statistically significant at level $\alpha=0.05$. For the significance test, a Welch two-sample $t$ test was employed using the t.test function in the $\mathrm{R}$ statistical software package (R Development Core Team 2013). The presence of colored bars along the $x$ axis in each Fig. 10 panel, where a specific color corresponds to a particular microphysics scheme, indicates that differences in the mean velocity component of the simulation were significantly different than those of the stage IV observations.

For the average $u$-velocity components (Figs. 10a,d,g,j), there is a clear diurnal cycle in both the simulations and

\footnotetext{
${ }^{4}$ Only objects with duration $>1 \mathrm{~h}$ and that are $\geq 2 \mathrm{~h}$ old at the forecast hour of interest have valid velocity components.
} 

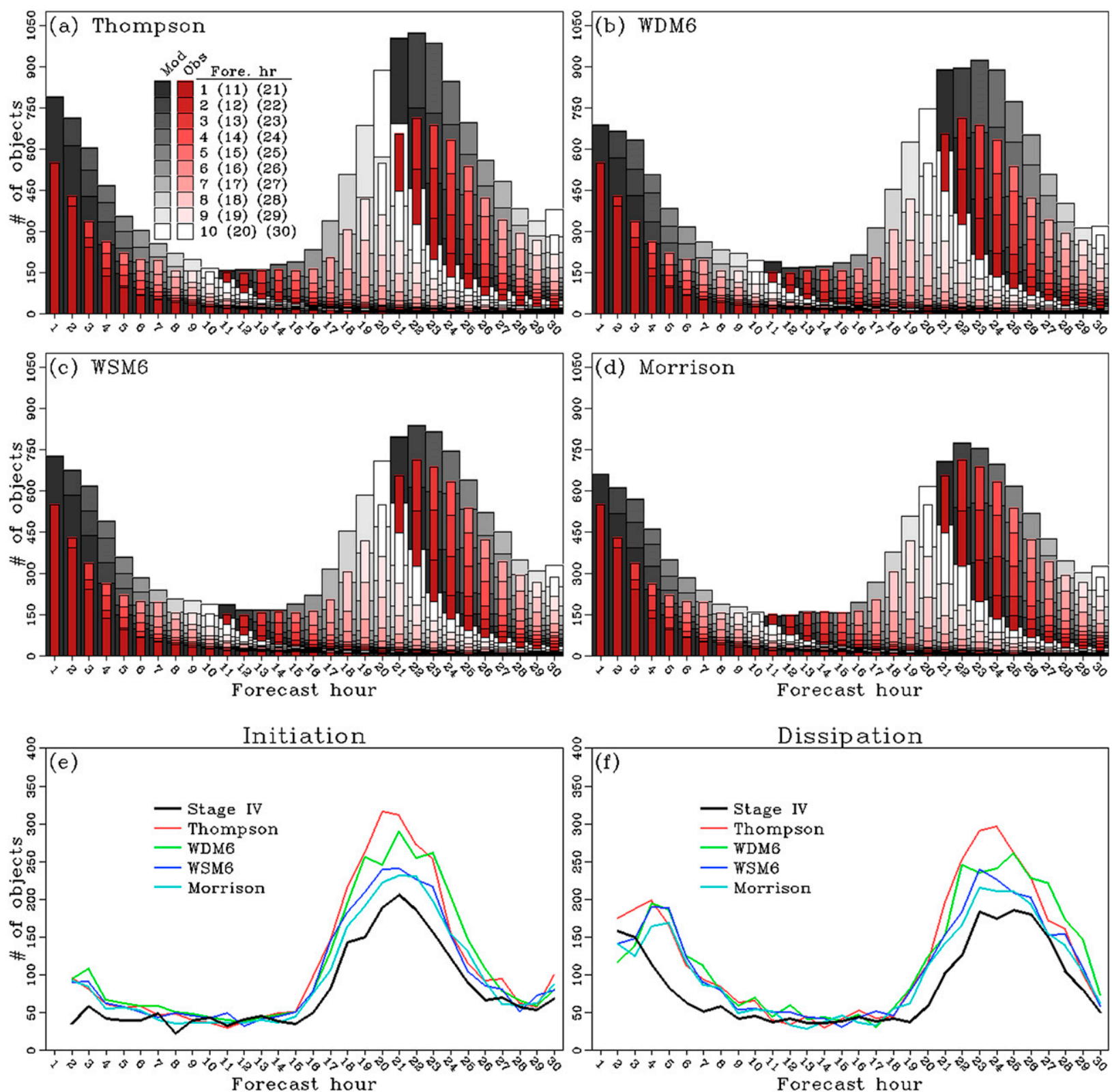

FIG. 8. As in Fig. 6, but for the 0.10-in. rainfall threshold and 16-km smoothing radius.

observations with a broad peak centered near forecast hour 12 and a broad minimum around forecast hours 2123. We believe this diurnal cycle is related to the large peak in initiating objects around forecast hour 21 (e.g., Fig. 6e). At this time, which corresponds to maximum insolation, airmass thunderstorms commonly occur in moist environments with weak upper-level flow that results in slow movement. Rainfall systems existing at other times within the diurnal cycle are more likely to be associated with a synoptic-scale weather system and/or be driven by mesoscale processes that require stronger vertical wind shear; thus, these types of systems would have faster speeds than the rainfall systems tied to solar heating.

Generally, average $u$ components in the simulations are slower than in observations. The differences are particularly large during the first $6-9 \mathrm{~h}$ of the forecasts when the simulations are too slow by anywhere from 4 to $8 \mathrm{~km} \mathrm{~h}^{-1}$, depending on which microphysics scheme, rainfall threshold, and smoothing radius is considered. This slow bias during the first part of the forecast has been documented for convection-allowing simulations that do not use radar data assimilation (Kain et al. 2010a). However, for simulations that use the radar-data-assimilating 

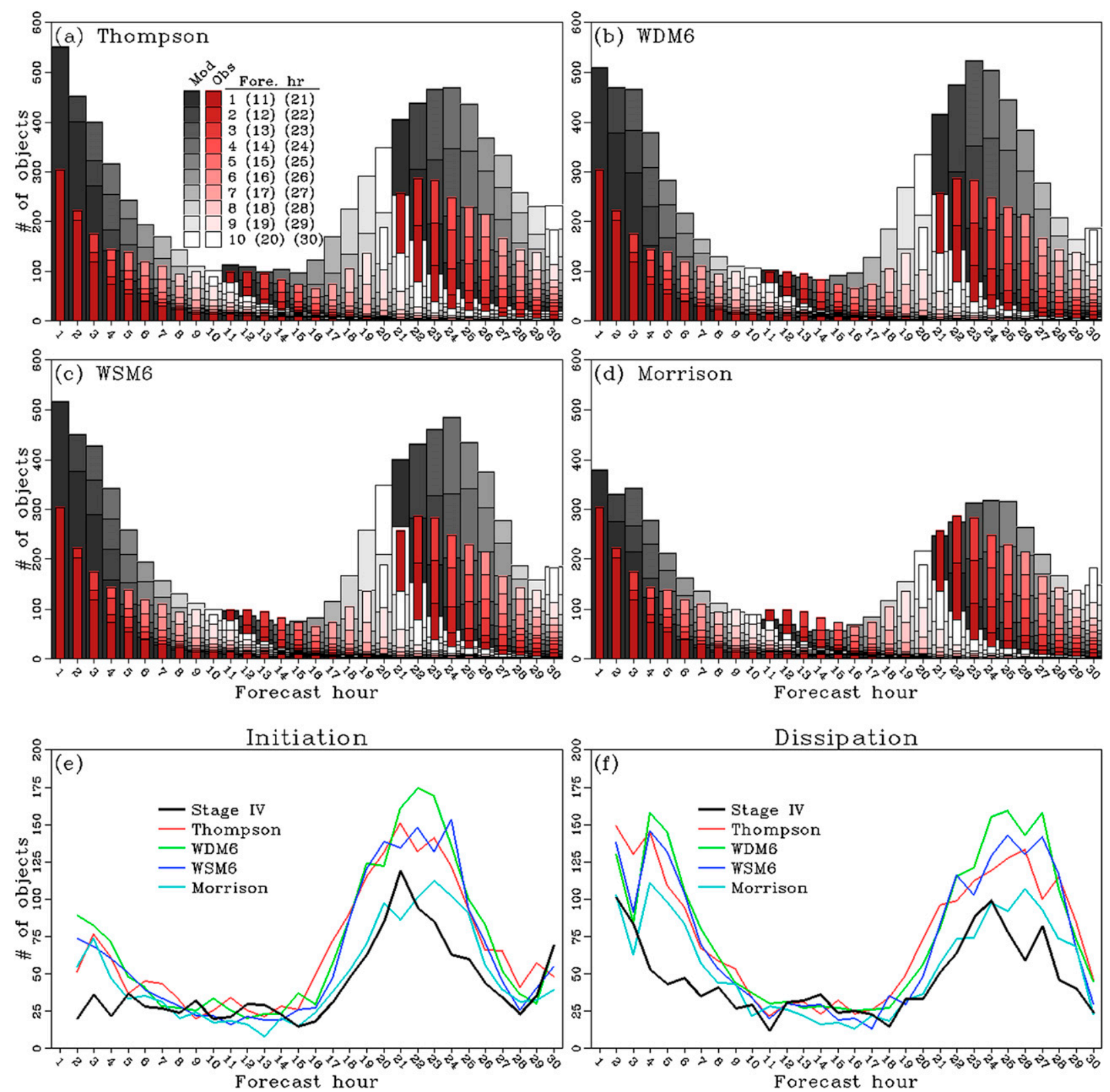

FIG. 9. As in Fig. 6, but for the 0.25 -in. rainfall threshold and 16-km smoothing radius.

3DVAR and cloud analysis system like those examined herein, only anecdotal evidence of a slow bias during the first few forecast hours has been documented during annual SFEs. The slow bias likely at least partially results from the 3DVAR and cloud analysis system not adequately depicting the mesoscale dynamics-circulations driving the movement of convective systems existing at the model initialization time. We have observed through model evaluations conducted for the annual SFEs that even when convection is well depicted in the initial conditions (ICs) of these simulations, there is often a period of time during the first hour or two of model integration when storms lose coherence but then "spin up" again as the model dynamics begin to take control. This spinup is likely reflected in the slow bias seen here.

To evaluate how much time-domain objects beginning from rainfall systems present in the ICs impact the average velocity components, Fig. 11 is constructed similarly to Fig. 10, except the averages do not include any observed or simulated objects that begin at forecast hour 1. For the average $u$ components (Figs. 11a,d,g,j) and 

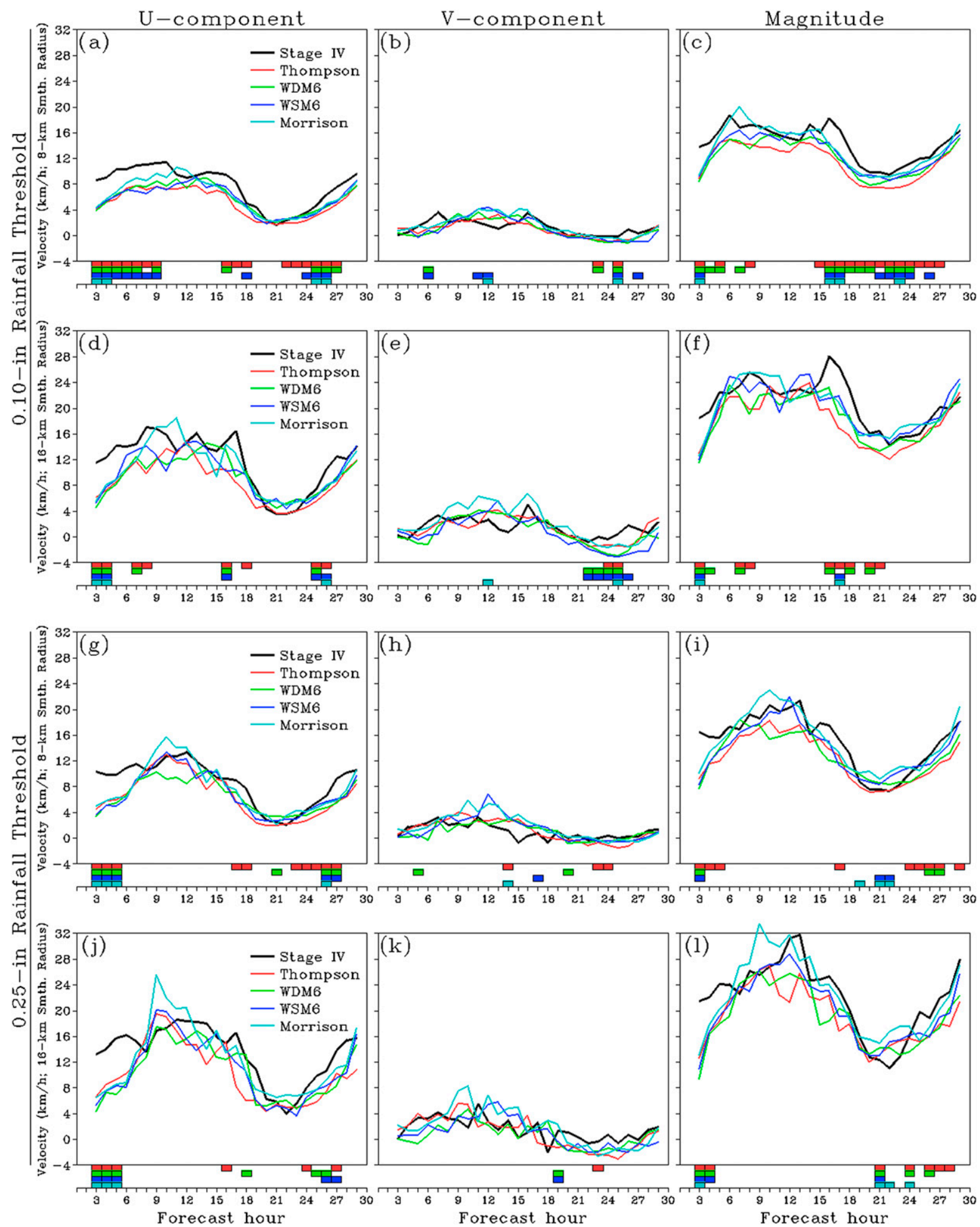

FIG. 10. Average velocity component and total magnitude at each forecast hour for time-domain objects in observations and simulations defined using the 0.10-in. rainfall threshold and 8-km smoothing radius: (a) $u$, (b) $v$, and (c) total magnitude. (d)-(f) As in (a)-(c), but for objects defined using a 16-km smoothing radius. (g)-(i), (j)-(1) As in (a)-(c), (d)-(f), respectively, except for objects defined using the 0.25in, rainfall threshold. A legend is provided in the left panels. The colored boxes just above the $x$ axis in each panel indicate that the differences at the particular hour between the simulation and observations are statistically significant. The colors indicated in the legend also apply to the filled boxes. 

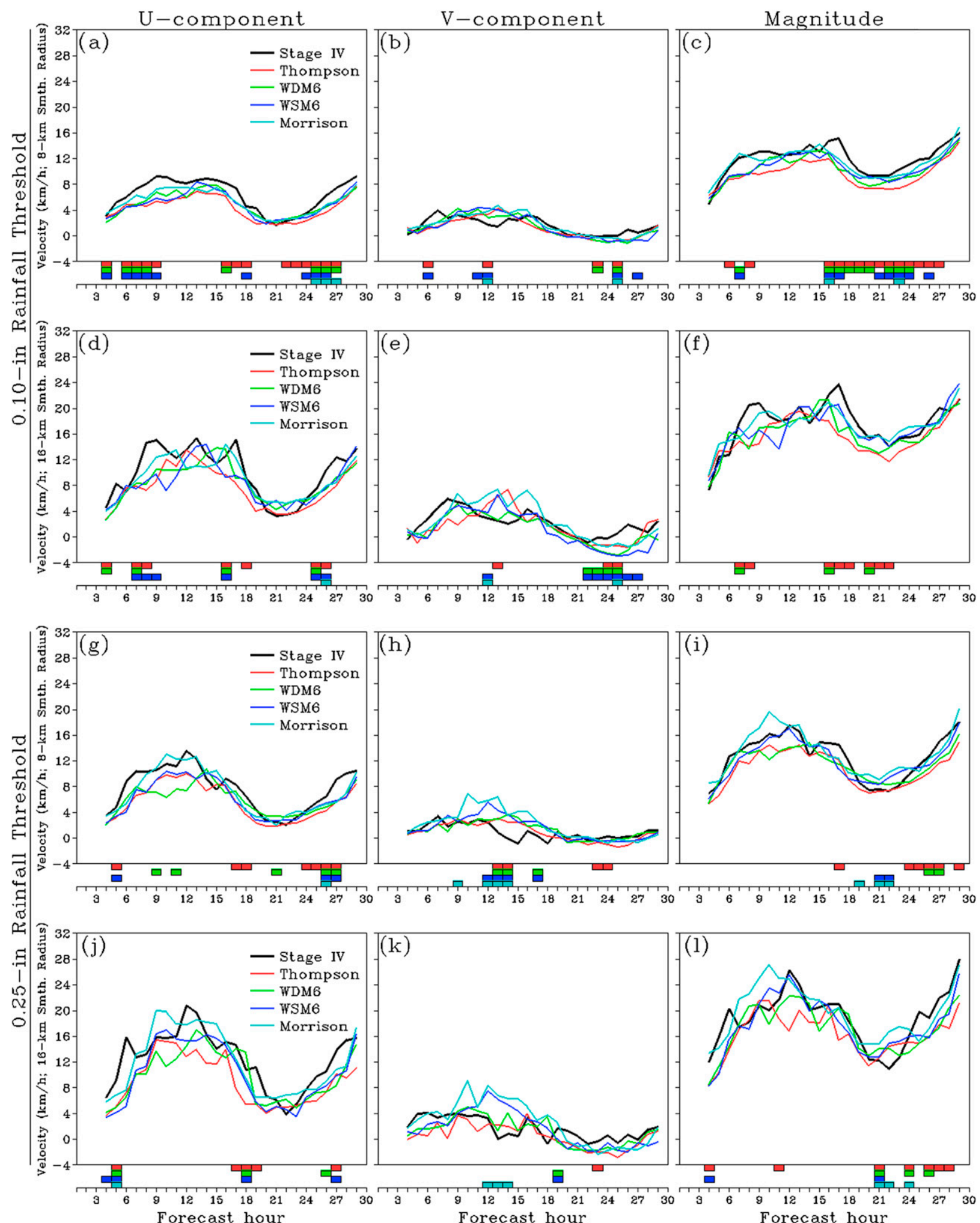

FIG. 11. As in Fig. 10, except observed and simulated objects that start at forecast hour 1 are not included in the averages. 
magnitudes (Figs. 11c,f,i,l), the differences between forecasts and observations at forecast hours 4-9 are much less relative to the corresponding Fig. 10 plots, which include the objects beginning at forecast hour 1 . This confirms that rainfall systems assimilated into the ICs through the radar-data-assimilating 3DVAR system [used at a single time without cycling; Xue et al. (2010)] are contributing much of the slow bias near the beginning of the forecast period. Thus, even though the radar data assimilation is beneficial during the first $0-12 \mathrm{~h}$ of the forecast, more sophisticated data assimilation methods like ensemble Kalman filters (e.g., Snyder and Zhang 2003; Tong and Xue 2005) may be needed to better depict storm and rainfall system dynamics at model initialization. Additionally, when used in a continuously cycled mode, assimilating radar data at higher frequencies (e.g., Hu and Xue 2007) is also likely to be beneficial.

The average $v$ components (Figs. 10b,e,h,k) in the simulations and observations generally fall within the range -4 to $4 \mathrm{~km} \mathrm{~h}^{-1}$, which is much smaller than the average $u$ components that vary between about 4 and $20 \mathrm{~km} \mathrm{~h}^{-1}$. Although there are a few times with statistically significant differences between the various simulations and observations, there do not appear to be any systematic differences with the exception of perhaps forecast hours 21-27 when the average $v$-velocity components in the simulations are generally smaller than those in the stage IV observations.

The average velocity magnitudes (Figs. 10c,f,i,l) generally follow the same pattern as the $u$ components, but with larger values-generally in the range $8-30 \mathrm{~km} \mathrm{~h}^{-1}$. Similar to the $u$ components, the simulations have a slow bias at most forecast hours. The Thompson scheme, on average, has the largest slow bias, and at each smoothing radius and rainfall threshold considered, Thompson has the most statistically significant differences.

To examine the evolution of the average wind components over the lifetime of time-domain objects, the average components are presented as a function of object duration in Fig. 12. This is equivalent to setting the initiation time of each object to a common hour and then computing the average components at each hour within the object's lifetime. Note that because the number of objects decreases sharply with increasing duration, the sample sizes used to compute the averages have a corresponding decrease with increasing duration. Thus, average velocities in the first few hours of object lifetimes are much more heavily weighted to objects with shorter lifetimes. In Fig. 12, the underlain gray bars indicate the sample size of the time-domain objects in the observations for each of the durations, and similar to Figs. 10 and 11, the colored bars along the $x$ axis of each panel show the object durations at which significant differences in average velocities between the simulations and observations were present.

For the average $u$ components (Figs. 12a,d,g,j), there is a clear upward trend in both simulations and observations with increasing object duration. Overall, the average $u$ velocities in the simulations are too slow, with the WDM6, WSM6, and Morrison simulations roughly clustered together and the Thompson simulations slower, which is reflected in there being more times at which the average $u$ velocities in Thompson are significantly different compared to the observations. The slow bias in all simulations is most pronounced during the first $8 \mathrm{~h}$ of an object's lifetime and for the 0.25 -in. rainfall threshold. The slow bias could be related to several factors, but we speculate that it is likely caused by an overprediction in the number of relatively slow-moving objects, and for the Thompson scheme, underprediction of cold pool strength, which would tend to slow simulated MCS propagation speeds.

For the average $v$ components (Figs. 12b,e,h,k), the observations generally stayed near zero, indicating that, on average, time-domain objects have no preference for northward or southward movement. For the 0.10-in. rainfall threshold, there is a slight tendency for systems to move more southerly with increasing lifetime, but for the 0.25 -in. threshold, the average $v$ velocities for observed time-domain objects stayed fairly constant and near zero. In general, the average $v$ velocities in the simulations were slightly less (i.e., more southerly) than the observations. In particular, at hours $6-10$ for the 0.10 -in. rainfall threshold and $16-\mathrm{km}$ smoothing radius (Fig. 12e) and hours 6-14 for the 0.25-in. threshold and 16-km smoothing (Fig. 12k), the average $v$ velocities in the WSM6 and WDM6 simulations were noticeably less than the observations indicating too much southerly movement.

Despite the aforementioned biases in the individual velocity components, the WSM6, WDM6, and Morrison simulations follow the observed average magnitudes very closely with only a few times near the beginning of the average time-domain object lifetime when the differences relative to the observations are significant (Figs. 12e,i,f,l). On the other hand, the average Thompson magnitudes are clearly outliers relative to the other runs, exhibiting obvious slow biases of about $6-8 \mathrm{~km} \mathrm{~h}^{-1}$. Thompson also has the most times at which differences relative to the observations are statistically significant. Furthermore, there is acceleration with increasing object lifetime similar to that observed in the average $u$ velocities, except the acceleration is even more pronounced. This acceleration could be real, or, if there is a tendency for shorter-lived objects to have slower speeds, it could 

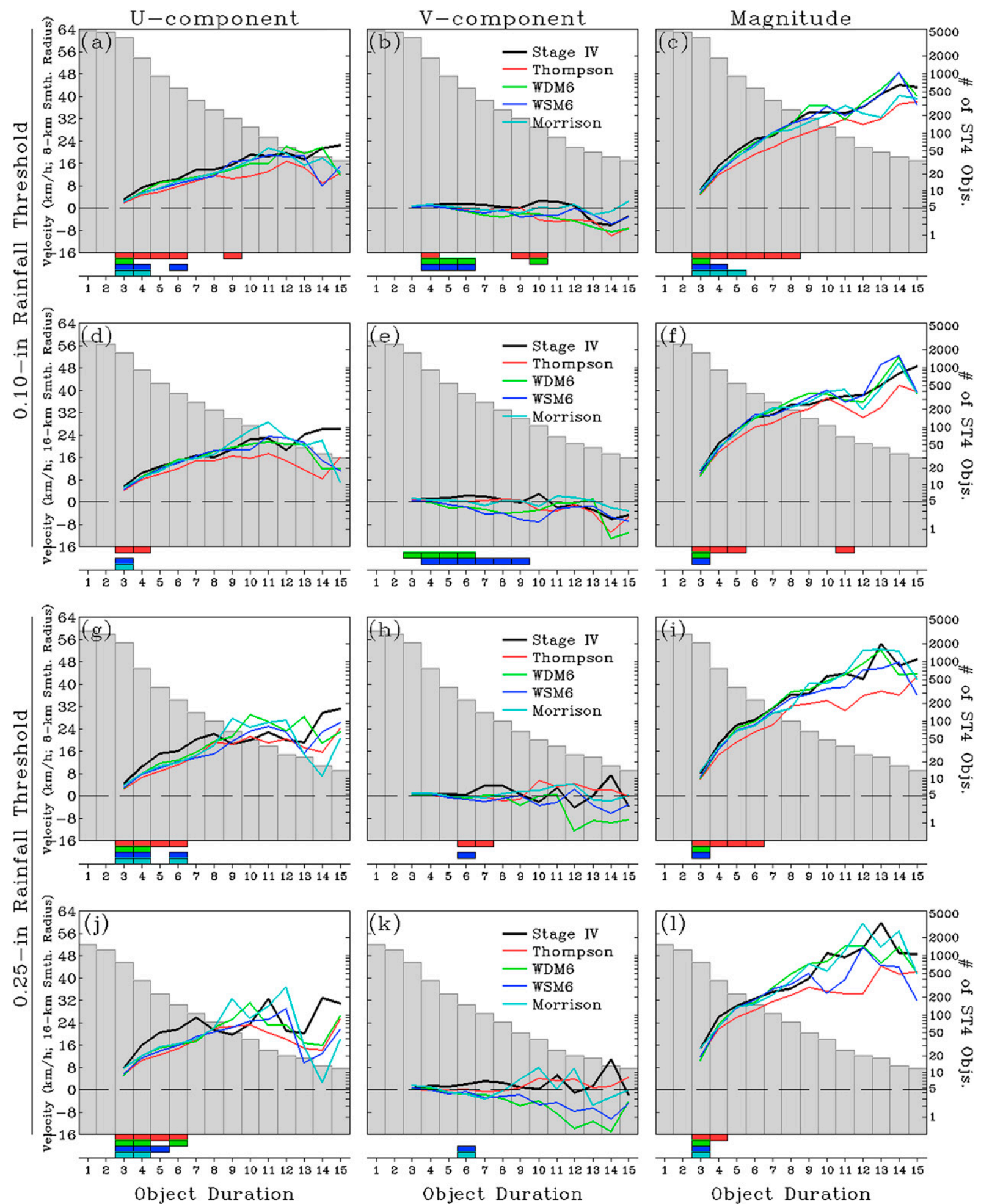

object Duration

FIG. 12. Colored lines indicate average velocity components $\left(\mathrm{km} \mathrm{h}^{-1}\right)$ for observations and simulations over the lifetime of time-domain objects. Gray histogram bars indicate the number of stage IV time-domain objects equal to or exceeding each value of duration. The $y$ axis for the velocities (number of objects) is on the lhs (rhs) of each panel. The colored boxes just above the $x$ axis in each panel indicate that the differences at the particular hour between the simulation and observations are statistically significant. The colors indicated in the legend in the middle column panels also apply to the filled boxes. For the 0.10 -in. rainfall threshold and 8-km smoothing radius, the (a) $u$, (b) $v$, and (c) total magnitudes are shown. (d)-(f) As in (a)-(c), but for the 16-km smoothing radius. (g)-(i), (j)-(l) As in (a)-(c), (d)-(f), respectively, but for the 0.25 -in. rainfall threshold. 

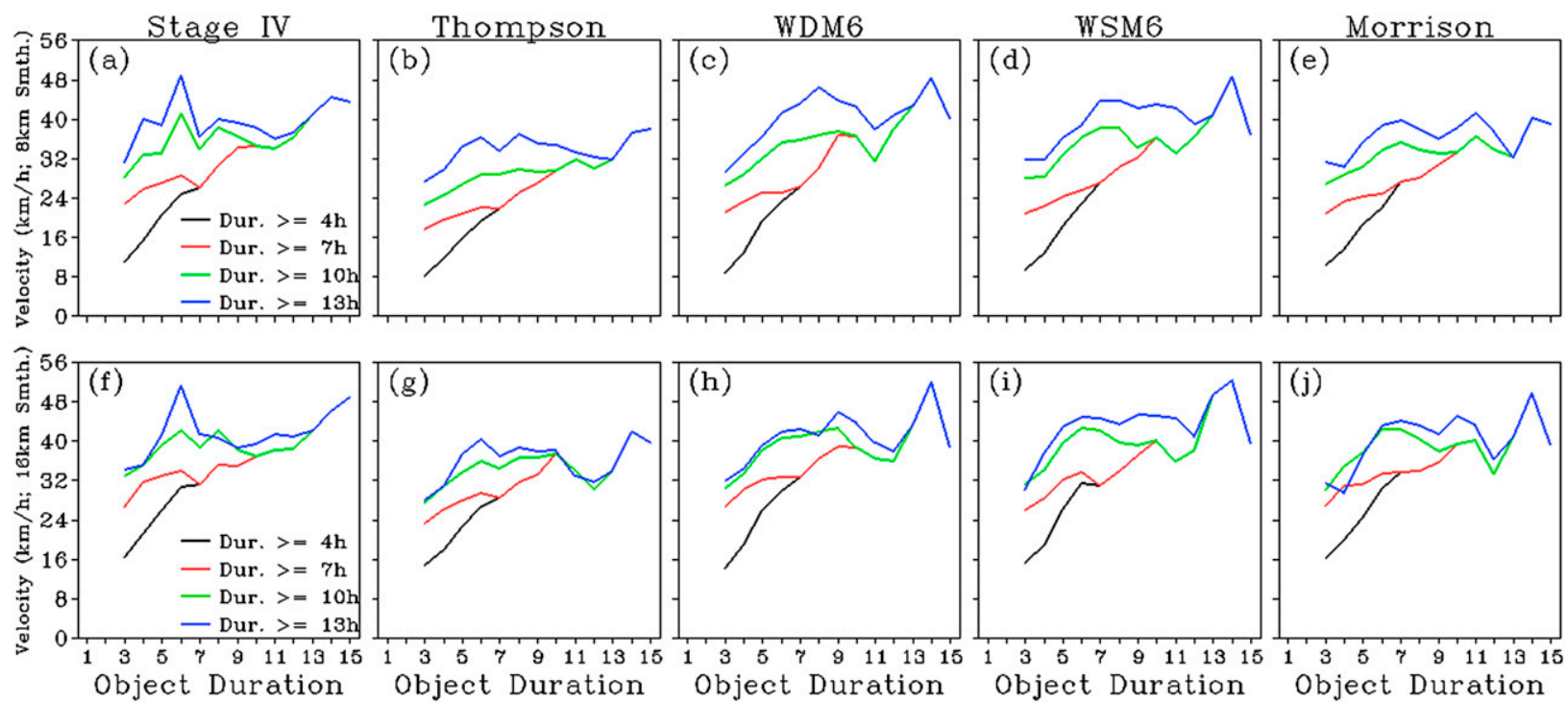

FIG. 13. Average speeds over the lifetime of time-domain objects defined using a rainfall threshold of 0.10 in. and smoothing radius of $8 \mathrm{~km}$ in (a) stage IV, (b) Thompson, (c) WDM6, (d) WSM6, and (e) Morrison. (f)-(j) As in (a)-(e), but for a 16-km smoothing radius. Black, red, green, and blue lines indicate averages computed only for objects that have lifetimes $\geq 4,7,10$, and $13 \mathrm{~h}$, respectively. A legend is provided at the bottom right of (a),(f).

simply be an artifact of these objects having more weight during the first few hours of the average object's lifetime.

To test the impact of time-domain object lifetime, Fig. 13 is constructed similarly to Fig. 12, except average speeds are computed separately for objects with total durations greater than $4,7,10$, and $13 \mathrm{~h}$. As longer durations are considered in Fig. 13, the average speeds during the beginning of the average object's lifetime increase, which eliminates much of the apparent acceleration. Thus, most of the apparent acceleration is, in fact, an artifact of the shorter-lifetime objects having slower speeds and more weight during the first few hours of the average object's lifetime. However, even just considering objects with duration greater than $13 \mathrm{~h}$, it appears that there is still an upward trend in object speed (i.e., acceleration) with increasing duration. This acceleration may reflect the typical evolution of organized convective systems. The beginning stages of these systems are often marked by the initiation of relatively small individual storms or multicell clusters of storms whose cold pools eventually merge to form one organized system. In the beginning stages of storm development, the movement of storms is largely determined by the mean wind; however, as storms merge and cold pool dynamics begin to dominate, convective systems can accelerate and propagate forward at speeds faster than the mean wind. The simulated cold pool dynamics are dependent on and very sensitive to the depiction of microphysical processes. Thus, the translation speed and evolution of simulated MCSs can vary greatly depending on the specific scheme (e.g., Adams-Selin et al. 2013).

\section{Summary and discussion}

In this study, a beta version of the Method for ObjectBased Diagnostic Evaluation (MODE) that incorporates the time dimension [known as MODE time-domain (MODE-TD)] was applied to 30-h precipitation forecasts from four members of the 2010 Storm-Scale Ensemble Forecast (SSEF) system with different microphysics parameterizations run by CAPS in support of the 2010 NOAA/HWT Spring Forecasting Experiment. In MODE$\mathrm{TD}$, contiguous regions of grid points exceeding a specified threshold encompassing both space and time are referred to as time-domain objects. The inclusion of time allows for the calculation of object attributes that provide information on object evolution such as lifetime, timing of initiation-dissipation, and translation, all of which would be difficult to diagnose by considering the spatial dimension alone. MODE-TD was applied to stage IV rainfall observations and the SSEF members using smoothing radii of 8,16 , and $32 \mathrm{~km}$ for rainfall thresholds of 0.10 and $0.25 \mathrm{in}$. Our main findings are summarized below.

For the spatial distribution of time-domain objects, it was found that for the smallest smoothing radius there was a clear maximum in both models and observations over the southeast United States. However, for larger smoothing radii, the spatial distribution of time-domain objects across the United States became more uniform. The elimination of the southeast U.S. maximum implied that objects there tend to be smaller, shorter lived, and less intense than those over other regions of the United 
States and thus more easily filtered out by a large smoothing radius. Additionally, for the largest smoothing radius and rainfall threshold, there was a broad region over the central United States where relatively long object tracks were concentrated, which likely reflects long-lived mesoscale convective systems, which are common in this region during spring and summer. All simulations overpredicted the total number of time-domain objects, with the Thompson scheme overpredicting the most and Morrison the least.

Examining distributions of object duration, it was found that for the smallest smoothing radius and rainfall threshold, the most common duration was $3 \mathrm{~h}$ in both the models and observations. With increased smoothing radius and rainfall threshold, the peak in the distributions shifted to shorter durations. The Morrison member stood out for matching the stage IV distributions much better than the other schemes, in particular, when the $16-\mathrm{km}$ smoothing radius was examined.

Examining the diurnal cycle of time-domain object frequencies, it was found that the simulations depict the shape of the diurnal cycle quite well, especially for the smallest smoothing radii and rainfall threshold, but overpredict object frequencies quite uniformly across all forecast hours. Using information provided by MODETD on time-domain object start and end times, it was also possible to examine the diurnal cycle of object initiation and dissipation frequencies. The simulations tended to have a spurious maximum in initiating objects during the first few hours of the forecast and a corresponding spurious maximum in dissipating objects a few hours later around forecast hours 3-5. Other than the spurious maxima, the phase of the main maxima in initiating and dissipating objects occurring at the latter part of the forecast period was well depicted.

Average $u$ (east-west) and $v$ (north-south) object movement velocity components as well as the total velocity magnitude were computed at each forecast hour for observed and simulated time-domain objects. For the average $u$ components and total magnitudes, the simulations tended to have a slow bias, which was most pronounced during the first $6 \mathrm{~h}$ of the forecasts. Much of this slow bias could be attributed to the inability of the noncycled 3DVAR and cloud analysis system that generates the model ICs to properly depict the mesoscale dynamics driving the movement of convective systems existing at the model initialization time. The slow bias was most dramatic in the Thompson member. Average velocity components were also computed over the lifetime of time-domain objects; that is, the start time of each object was set to a common hour and then averages were computed at each subsequent hour. Again, a slow bias in the simulations was found, with the bias in the
Thompson member the most pronounced. Furthermore, in both models and observations, an upward trend in the $u$-velocity components and total magnitudes was observed. The upward trend was mainly an artifact of shorter-duration objects having slower speeds and more weight during the first few hours of the average object's lifetime. However, after only considering the longerduration objects in the average speeds, there still appeared to be a slight acceleration with increasing object duration. It is possible that the acceleration reflects the typical evolution of organized convective systems that start with discrete storms or multicell storm clusters that move with the mean wind and then merge-grow upscale into a single forward-propagating system that moves faster than the mean wind.

The slow bias observed in the Thompson member was somewhat of a surprise given the subjective findings from the 2010 Spring Forecasting Experiment, which suggested that Thompson did not have any systematic bias in translation speed. As discussed earlier, as part of the model evaluations during SFE2010 it was noted that, in the latter portions of the 30 -h forecasts, the nonThompson schemes tended to generate stronger (i.e., colder) cold pools and associated MCSs that propagated too quickly east and/or south, while the Thompson member had weaker cold pools that appeared to be associated with MCSs that propagated more slowly, which better matched the observations. The subjective finding that the Thompson member did not move MCSs as quickly east and/or south as the non-Thompson members is consistent with the findings herein that Thompson had the slowest-moving rainfall systems. However, rather than having systems that translated too quickly, the non-Thompson members were found to have translation speeds that were on average about the same or slightly slower than the observations. We suspect this discrepancy is simply a result of the narrow focus of the subjective Spring Forecasting Experiment comparisons, which were conducted for a limited number of cases and over relatively small subdomains of the model simulations, whereas the objective results from MODE-TD considered much more data.

The addition of the time dimension in the MODE-TD software allowed for relatively straightforward evaluation of rainfall system attributes that should be very useful to model users and developers. In the future, we believe that MODE-TD concepts will continue to have particularly useful applications to convection-allowing (i.e., sub-4-km grid spacing) forecast systems, because it will allow for an efficient and objective method for evaluating explicitly depicted convective phenomena such as supercells, MCSs, and flash-flood-producing rainfall systems. This future work will require the adaptation of 
fuzzy-logic-based algorithms used for matching and/or merging spatial objects (e.g., Davis et al. 2009; Johnson et al. 2011a; Johnson and Wang 2013) to time-domain objects, which was not attempted in this study.

Acknowledgments. Support for this project was provided by the Developmental Testbed Center (DTC). The DTC Visitor Program is funded by the National Oceanic and Atmospheric Administration, the National Center for Atmospheric Research and the National Science Foundation. Funding was also provided by NOAA/ Office of Oceanic and Atmospheric Research under NOAA-University of Oklahoma Cooperative Agreement \#NA17RJ1227, U.S. Department of Commerce. CAPS SSEF forecasts were supported by the NOAA Collaborative Science, Technology, and Applied Research (CSTAR) Program with supplementary support from NSF grant AGS-0802888. M. Xue was also supported by NSF grants OCI-0905040, AGS-0941491, AGS-1046171, and AGS-1046081. CAPS forecasts were supported by an allocation through the XSEDE supercomputing program supported by the National Science Foundation. The computations were performed on Athena (a Cray XT4) at the National Institute for Computational Science (http://www.nics.tennessee.edu/). CAPS also utilized resources from the OU Supercomputing Center for Research and Education for ensemble post-processing. We thank three anonymous reviewers for providing very helpful comments/suggestions that improved the manuscript.

\section{REFERENCES}

Accadia, C., S. Mariani, M. Casaioli, A. Lavagnini, and A. Speranza, 2003: Sensitivity of precipitation forecast skill scores to bilinear interpolation and a simple nearest-neighbor average method on high-resolution verification grids. Wea. Forecasting, 18, 918-932, doi:10.1175/1520-0434(2003)018<0918: SOPFSS $>2.0 . \mathrm{CO} ; 2$.

Adams-Selin, R. D., S. C. van den Heever, and R. H. Johnson, 2013: Sensitivity of bow-echo simulation to microphysical parameterizations. Wea. Forecasting, 28, 1188-1209, doi:10.1175/ WAF-D-12-00108.1.

Ahijevych, D. A., C. A. Davis, R. E. Carbone, and J. D. Tuttle, 2004: Initiation of precipitation episodes relative to elevated terrain. J. Atmos. Sci., 61, 2763-2769, doi:10.1175/JAS3307.1.

Baldwin, M. E., and K. E. Mitchell, 1997: The NCEP hourly multisensory U.S. precipitation analysis for operations and GCIP research. Preprints, 13th Conf. on Hydrology, Long Beach, CA, Amer. Meteor. Soc., 54-55.

Bryan, G. H., and H. Morrison, 2012: Sensitivity of a simulated squall line to horizontal resolution and parameterization of microphysics. Mon. Wea. Rev., 140, 202-225, doi:10.1175/ MWR-D-11-00046.1.

Bullock, R., 2011: Development and implementation of MODE time domain object-based verification. Preprints, 24th Conf. on Weather and Forecasting/20th Conf. on Numerical Weather
Prediction, Seattle, WA, Amer. Meteor. Soc., 96. [Available online at https://ams.confex.com/ams/91Annual/webprogram/ Paper182677.html.]

Carbone, R. E., J. D. Tuttle, D. A. Ahijevych, and S. B. Trier, 2002: Inferences of predictability associated with warm season precipitation episodes. J. Atmos. Sci., 59, 2033-2056, doi:10.1175/ 1520-0469(2002)059<2033:IOPAWW>2.0.CO;2.

Casati, B., and Coauthors, 2008: Forecast verification: Current status and future directions. Meteor. Appl., 15,3-18, doi:10.1002/ met.52.

Chen, F., and J. Dudhia, 2001: Coupling an advanced land surfacehydrology model with the Penn State-NCAR MM5 modeling system. Part I: Model description and implementation. Mon. Wea. Rev., 129, 569-585, doi:10.1175/1520-0493(2001)129<0569: CAALSH $>2.0 . \mathrm{CO} ; 2$.

Chou, M.-D., and M. J. Suarez, 1994: An efficient thermal infrared radiation parameterization for use in general circulation models. NASA Tech. Memo. 104606, Vol. 3, 85 pp.

Clark, A. J., W. A. Gallus Jr., M. Xue, and F. Kong, 2009: A comparison of precipitation forecast skill between small convection-allowing and large convection-parameterizing ensembles. Wea. Forecasting, 24, 1121-1140, doi:10.1175/ 2009WAF2222222.1.

$\longrightarrow,-$, and M. L. Weisman, 2010: Neighborhood-based verification of precipitation forecasts from convection-allowing NCAR WRF model simulations and the operational NAM. Wea. Forecasting, 25, 1495-1509, doi:10.1175/ 2010WAF2222404.1.

— Weather Testbed Experimental Forecast Program Spring Experiment. Bull. Amer. Meteor. Soc., 93, 55-74, doi:10.1175/ BAMS-D-11-00040.1.

_ J. S. Kain, P. T. Marsh, J. Correia Jr., M. Xue, and F. Kong, 2012b: Forecasting tornado pathlengths using a threedimensional object identification algorithm applied to convection-allowing forecasts. Wea. Forecasting, 27, 10901113, doi:10.1175/WAF-D-11-00147.1.

— J. Jao, P. T. Marsh, T. Smith, J. S. Kain, J. Correia Jr., M. Xue, and F. Kong, 2013: Tornado pathlength forecasts from 2010 to 2011 using ensemble updraft helicity. Wea. Forecasting, 28, 387-407, doi:10.1175/WAF-D-12-00038.1.

Davis, C. A., B. Brown, and R. Bullock, 2006a: Object-based verification of precipitation forecasts. Part I: Methodology and application to mesoscale rain areas. Mon. Wea. Rev., 134, 1772-1784, doi:10.1175/MWR3145.1.

,-- , and - 2006b: Object-based verification of precipitation forecasts. Part II: Application to convective rain systems. Mon. Wea. Rev., 134, 1785-1795, doi:10.1175/MWR3146.1.

- $-\ldots$, , and J. Halley-Gotway, 2009: The Method for Object-Based Diagnostic Evaluation (MODE) applied to numerical forecasts from the 2005 NSSL/SPC Spring Program. Wea. Forecasting, 24, 1252-1267, doi:10.1175/ 2009WAF2222241.1.

Dawson, D. T., II, M. Xue, J. A. Milbrandt, and M. K. Yau, 2010: Comparison of evaporation and cold pool development between single-moment and multimoment bulk microphysics schemes in idealized simulations of tornadic thunderstorms. Mon. Wea. Rev., 138,1152-1171, doi:10.1175/2009MWR2956.1.

Duda, J. D., and W. A. Gallus Jr., 2013: The impact of large-scale forcing on skill of simulated convective initiation and upscale evolution with convection-allowing grid-spacings in the WRF. Wea. Forecasting, 28, 994-1018, doi:10.1175/ WAF-D-13-00005.1. 
Ebert, E. E., and J. L. McBride, 2000: Verification of precipitation in weather systems: Determination of systematic errors. J. Hydrol., 239, 179-202, doi:10.1016/S0022-1694(00)00343-7.

—_, and W. A. Gallus Jr., 2009: Toward better understanding of the contiguous rain area (CRA) method for spatial forecast verification. Wea. Forecasting, 24, 1401-1415, doi:10.1175/ 2009WAF2222252.1.

Gao, J., M. Xue, K. Brewster, and K. K. Droegemeier, 2004: A threedimensional variational data analysis method with recursive filter for Doppler radars. J. Atmos. Oceanic Technol., 21, 457-469, doi:10.1175/1520-0426(2004)021<0457:ATVDAM>2.0.CO;2.

Hong, S.-Y., and J.-O. J. Lim, 2006: The WRF single-moment 6class microphysics scheme (WSM6). J. Korean Meteor. Soc., 42, 129-151.

$\mathrm{Hu}, \mathrm{M}$., and M. Xue, 2007: Impact of configurations of rapid intermittent assimilation of WSR-88D radar data for the 8 May 2003 Oklahoma City tornadic thunderstorm case. Mon. Wea. Rev., 135, 507-525, doi:10.1175/MWR3313.1.

— - — , and K. Brewster, 2006: 3DVAR and cloud analysis with WSR-88D level-II data for the prediction of Fort Worth tornadic thunderstorms. Part I: Cloud analysis and its impact. Mon. Wea. Rev., 134, 675-698, doi:10.1175/MWR3092.1.

Janjić, Z. I., 2002: Nonsingular implementation of the MellorYamada level 2.5 scheme in the NCEP Meso Model. NCEP Office Note 437, $61 \mathrm{pp}$.

Jensen, T., and Coauthors, 2010: An overview of the objective evaluation performed during the Hazardous Weather Testbed (HWT) 2010 Spring Experiment. Preprints, 25th Conf. on Severe Local Storms, Denver, CO, Amer. Meteor. Soc., 13B.1. [Available online at http://ams.confex.com/ams/25SLS/ techprogram/paper_175848.htm.]

Johnson, A., and X. Wang, 2012: Verification and calibration of neighborhood and object-based probabilistic precipitation forecasts from a multimodel convection-allowing ensemble. Mon. Wea. Rev., 140, 3054-3077, doi:10.1175/MWR-D-11-00356.1.

—, and —, 2013: Object-based evaluation of a storm-scale ensemble during the 2009 NOAA Hazardous Weather Testbed Spring Experiment. Mon. Wea. Rev., 141, 1079-1098, doi:10.1175/MWR-D-12-00140.1.

_, , F. Kong, and M. Xue, 2011a: Hierarchical cluster analysis of a convection-allowing ensemble during the Hazardous Weather Testbed 2009 Spring Experiment. Part I: Development of the object-oriented cluster analysis method for precipitation fields. Mon. Wea. Rev., 139, 3673-3693, doi:10.1175/MWR-D-11-00015.1.

,,--- , and $-2011 \mathrm{~b}$ : Hierarchical cluster analysis of a convection-allowing ensemble during the Hazardous Weather Testbed 2009 Spring Experiment. Part II: Ensemble clustering over the whole experiment period. Mon. Wea. Rev., 139, 3694-3710, doi:10.1175/MWR-D-11-00016.1.

,,--- , and,- 2013 : Object-based evaluation of the impact of horizontal grid spacing on convection-allowing forecasts. Mon. Wea. Rev., 141, 3413-3425, doi:10.1175/ MWR-D-13-00027.1.

Jung, Y., M. Xue, and M. Tong, 2012: Ensemble Kalman filter analyses of the 29-30 May 2004 Oklahoma tornadic thunderstorm using one- and two-moment bulk microphysics schemes, with verification against polarimetric radar data. Mon. Wea. Rev., 140, 1457-1475, doi:10.1175/MWR-D-11-00032.1.

Kain, J. S., and Coauthors, 2008: Some practical considerations regarding horizontal resolution in the first generation of operational convection-allowing NWP. Wea. Forecasting, 23, 931-952, doi:10.1175/WAF2007106.1.
— , and Coauthors, 2010a: Assessing advances in the assimilation of radar data and other mesoscale observations within a collaborative forecasting-research environment. Wea. Forecasting, 25, 1510-1521, doi:10.1175/2010WAF2222405.1.

, S. R. Dembek, S. J. Weiss, J. L. Case, J. J. Levit, and R. A. Sobash, 2010b: Extracting unique information from highresolution forecast models: Monitoring selected fields and phenomena every time step. Wea. Forecasting, 25, 1536-1542, doi:10.1175/2010WAF2222430.1.

_ - and Coauthors, 2013: A feasibility study for probabilistic convection initiation forecasts based on explicit numerical guidance. Bull. Amer. Meteor. Soc., 94, 1213-1225, doi:10.1175/ BAMS-D-11-00264.1.

Kong, F., and Coauthors, 2010: Evaluation of CAPS multi-model storm-scale ensemble forecast for the NOAA HWT 2010 Spring Experiment. Preprints, 25th Conf. on Severe Local Storms, Amer. Meteor. Soc., P4.18. [Available online at https://ams.confex.com/ams/pdfpapers/175822.pdf.]

Lack, S., G. L. Limpert, and N. I. Fox, 2010: An object-oriented multiscale verification scheme. Wea. Forecasting, 25, 79-92, doi:10.1175/2009WAF2222245.1.

Lakshmanan, V., K. Hondl, and R. Rabin, 2009: An efficient, general-purpose technique for identifying storm cells in geospatial images. J. Atmos. Oceanic Technol., 26, 523-537, doi:10.1175/2008JTECHA1153.1.

Lim, K.-S. S., and S.-Y. Hong, 2010: Development of an effective double-moment cloud microphysics scheme with prognostic cloud condensation nuclei (CCN) for weather and climate models. Mon. Wea. Rev., 138, 1587-1612, doi:10.1175/ 2009MWR2968.1.

Lorenz, E. N., 1969: The predictability of a flow which possesses many scales of motion. Tellus, 21, 289-307, doi:10.1111/ j.2153-3490.1969.tb00444.x.

Mellor, G. L., and T. Yamada, 1982: Development of a turbulence closure model for geophysical fluid problems. Rev. Geophys., 20, 851-875, doi:10.1029/RG020i004p00851.

Miller, S., and J. Correia Jr., 2012: Preliminary assessment of timing differences between convective initiation and severe initiation. Preprints, 26th Conf. on Severe Local Storms, Nashville, TN, Amer. Meteor. Soc., 135. [Available online at https://ams. confex.com/ams/26SLS/webprogram/Paper212595.html.]

Mlawer, E. J., S. J. Taubman, P. D. Brown, M. J. Iacono, and S. A. Clough, 1997: Radiative transfer for inhomogeneous atmosphere: RRTM, a validated correlated-k model for the longwave. J. Geophys. Res., 102, 16663-16682, doi:10.1029/ 97JD00237.

Morrison, H., J. A. Curry, and V. I. Khvorostyanov, 2005: A new double-moment microphysics parameterization for application in cloud and climate models. Part I: Description. J. Atmos. Sci., 62, 1665-1677, doi:10.1175/JAS3446.1.

Nachamkin, J. E., 2004: Mesoscale verification using meteorological composites. Mon. Wea. Rev., 132, 941-955, doi:10.1175/ 1520-0493(2004)132<0941:MVUMC>2.0.CO;2.

Putnam, B. J., M. Xue, Y. Jung, N. A. Snook, and G. Zhang, 2014: The analysis and prediction of microphysical states and polarimetric variables in a mesoscale convective system using double-moment microphysics, multinetwork radar data, and the ensemble Kalman filter. Mon. Wea. Rev., 142, 141-162, doi:10.1175/MWR-D-13-00042.1.

R Development Core Team, cited 2013: R: A language and environment for statistical computing. R Foundation for Statistical Computing, Vienna, Austria. [Available online at http://www. R-project.org.] 
Roberts, N. M., and H. W. Lean, 2008: Scale-selective verification of rainfall accumulations from high-resolution forecasts of convective events. Mon. Wea. Rev., 136, 78-97, doi:10.1175/ 2007MWR2123.1.

Rogers, E., and Coauthors, 2009: The NCEP North American Mesoscale modeling system: Recent changes and future plans. Preprints, 23rd Conf. on Weather Analysis and Forecasting/ 19th Conf. on Numerical Weather Prediction, Omaha, NE, Amer. Meteor. Soc., 2A.4. [Available online at https://ams. confex.com/ams/pdfpapers/154114.pdf.]

Schwartz, C. S., and Coauthors, 2010: Toward improved convection-allowing ensembles: Model physics sensitivities and optimizing probabilistic guidance with small ensemble membership. Wea. Forecasting, 25, 263-280, doi:10.1175/ 2009WAF2222267.1.

Skamarock, W. C., and M. L. Weisman, 2009: The impact of positive-definite moisture transport on NWP precipitation forecasts. Mon. Wea. Rev., 137, 488-494, doi:10.1175/ 2008MWR2583.1.

— - and Coauthors, 2008: A description of the Advanced Research WRF version 3. NCAR Tech Note NCAR/TN475+STR, 113 pp. [Available online at http://www.mmm.ucar. edu/wrf/users/docs/arw_v3.pdf.]

Snyder, C., and F. Zhang, 2003: Assimilation of simulated Doppler radar observations with an ensemble Kalman filter. Mon. Wea. Rev., 131, 1663-1677, doi:10.1175//2555.1.

Thompson, G., R. M. Rasmussen, and K. Manning, 2004: Explicit forecasts of winter precipitation using an improved bulk microphysics scheme. Part I: Description and sensitivity analysis. Mon. Wea. Rev., 132, 519-542, doi:10.1175/ 1520-0493(2004)132<0519:EFOWPU>2.0.CO;2.

Tong, M., and M. Xue, 2005: Ensemble Kalman filter assimilation of Doppler radar data with a compressible nonhydrostatic model: OSS experiments. Mon. Wea. Rev., 133, 1789-1807, doi:10.1175/MWR2898.1.

Tuttle, J. D., and C. A. Davis, 2006: Corridors of warm season precipitation in the central United States. Mon. Wea. Rev., 134, 2297-2317, doi:10.1175/MWR3188.1.

Wernli, H., M. Paulat, M. Hagen, and C. Frei, 2008: SAL-A novel quality measure for the verification of quantitative precipitation forecasts. Mon. Wea. Rev., 136, 4470-4487, doi:10.1175/2008MWR2415.1.

Xue, M., D. Wang, J. Gao, K. Brewster, and K. K. Droegemeier, 2003: The Advanced Regional Prediction System (ARPS), storm-scale numerical weather prediction and data assimilation. Meteor. Atmos. Phys., 82, 139-170, doi:10.1007/ s00703-001-0595-6.

— , and Coauthors, 2008: CAPS realtime storm-scale ensemble and high-resolution forecasts as part of the NOAA Hazardous Weather Testbed 2008 Spring Experiment. Preprints, 24th Conf. Severe Local Storms, Savannah, GA, Amer. Meteor. Soc., 12.2. [Available online at https://ams.confex.com/ams/pdfpapers/ 142036.pdf.]

and Coauthors, 2010: CAPS realtime storm-scale ensemble and high-resolution forecasts for the NOAA Hazardous Weather Testbed 2010 Spring Experiment. Preprints, 25th Conf. on Severe Local Storms, Denver, CO, Amer. Meteor. Soc., 7B.3. [Available online at https://ams.confex.com/ams/pdfpapers/176056.pdf.] 